OPEN ACCESS

Edited by:

Trinidad Montero-Melendez, Queen Mary University of London, United Kingdom

Reviewed by: Niccolo Terrando, Duke University, United States Matthew Spite, Harvard Medical School, United States

*Correspondence: Antonio Recchiuti a.recchiuti@unich.it

Specialty section: This article was submitted to Inflammation Pharmacology, a section of the journal Frontiers in Pharmacology

Received: 13 December 2018 Accepted: 28 February 2019

Published: 02 April 2019

Citation:

Recchiuti A, Mattoscio D and Isopi E (2019) Roles, Actions, and Therapeutic Potential of Specialized

Pro-resolving Lipid Mediators for the Treatment of Inflammation in Cystic Fibrosis.

Front. Pharmacol. 10:252. doi: 10.3389/fphar.2019.00252

\section{Roles, Actions, and Therapeutic Potential of Specialized Pro-resolving Lipid Mediators for the Treatment of Inflammation in Cystic Fibrosis}

\author{
Antonio Recchiuti ${ }^{1,2 *}$, Domenico Mattoscio ${ }^{1,2}$ and Elisa Isopi ${ }^{1,2}$ \\ 'Department of Medical, Oral and Biotechnological Science, Università "G. d'Annunzio" Chieti-Pescara, Chieti, Italy, \\ ${ }^{2}$ Centro di Scienze dell'Invecchiamento e Medicina Traslazionale (CeSI-MeT), Università "G. d'Annunzio" Chieti-Pescara, \\ Chieti, Italy
}

Non-resolving inflammation is the main mechanism of morbidity and mortality among patients suffering from cystic fibrosis (CF), the most common life-threatening human genetic disease. Resolution of inflammation is an active process timely controlled by endogenous specialized pro-resolving lipid mediators (SPMs) produced locally in inflammatory loci to restrain this innate response, prevent further damages to the host, and permit return to homeostasis. Lipoxins, resolvins, protectins, and maresins are SPM derived from polyunsaturated fatty acids that limit excessive leukocyte infiltration and pro-inflammatory signals, stimulate innate microbial killing, and enhance resolution. Their unique chemical structures, receptors, and bioactions are being elucidated. Accruing data indicate that SPMs carry protective functions against unrelenting inflammation and infections in preclinical models and human CF systems. Here, we reviewed their roles and actions in controlling resolution of inflammation, evidence for their impairment in CF, and proofs of principle for their exploitation as innovative, non-immunosuppressive drugs to address inflammation and infections in CF.

Keywords: resolution, lipid mediator, pharmacology, macrophages, lung inflammation and fibrosis, homeostasis, chronic infections, Pseudomonas aeruginosa

\section{ACUTE INFLAMMATION AND RESOLUTION: DEFINITIONS AND KEY MECHANISMS}

Acute inflammation is a protective process arising in vascularized tissues upon damages, altered homeostasis, and infections. Its macroscopic hallmarks, or "cardinal signs," identified by Celsus in the first century BC encompass rubor (redness), tumor (swelling), calor (heat), and dolor (pain) (Majno, 1991), which arise from responses of tissue resident and blood-borne cells that are regulated by chemical signals, such as prostaglandins (PG), thromboxane (TX), leukotrienes (LT), cytokines, and chemokines. Increase in permeability of microvessels determines plasma fluid leakage and accumulation in tissues, leading to edema (Figure 1). This is followed by polymorphonuclear neutrophil (PMN) recruitment, adhesion to vascular endothelial cells, diapedesis (or transmigration), and accumulation or swarming. Their primary function is to eliminate 


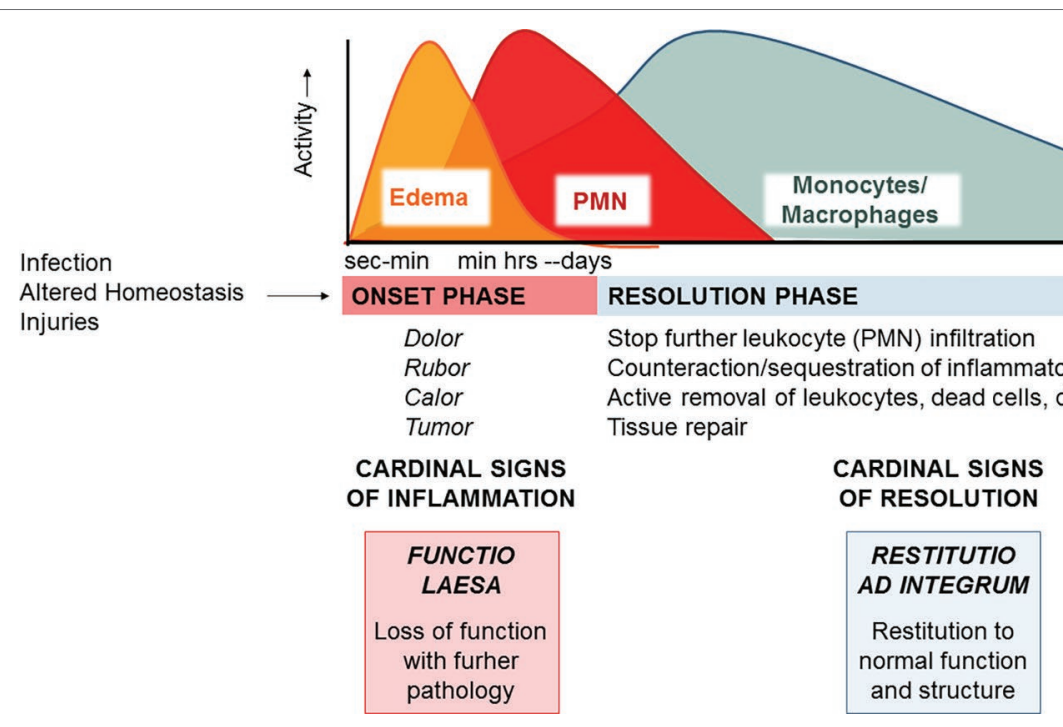

FIGURE 1 | The acute inflammatory response and its ideal outcome: essential steps, mechanisms, and definitions. Injury, infections, or dysregulated homeostasis ignites the acute inflammatory response that is normally a host protective mechanism. The first event in acute inflammation is edema formation, followed by infiltration of PMN, and then monocyte and macrophages that clear PMN leading to resolution, which is essential for ensuring host protection and sparing from tissue damage.

bacteria or other damaging substances mainly via phagocytosis, i.e., the engulfment of foreign bodies inside intracellular vacuoles (phagosomes) and their disposition (Gordon, 2016). PMNs also release their granule contents, DNA, and chromatin proteins to form extracellular fibers that immobilize and kill bacteria. Neutrophil extracellular traps (NETs) represent a potent, innate mechanism by which PMNs prevent microbe spreading following infection (Brinkmann et al., 2004). PMNs undergo rapid apoptosis and are actively removed by macrophages (MФs) differentiated from monocytes entering as a second wave in inflamed tissues in a process termed "efferocytosis" (deCathelineau and Henson, 2003). Studies also indicate that PMNs can exit the inflammatory loci via lymphatic vessels or lining adipose tissue (lipopassage) (Schwab et al., 2007). MФs are also capable of clearing bacteria, pathogenic substances, and debris. Ideally, their action occurs in a non-phlogistic way and allows the resolution of inflammation (Serhan et al., 2007). Cardinal signs of resolution are: (1) limitation/cessation of PMN infiltration, (2) sequestration and counter-regulation of pro-inflammatory chemical mediators, (3) apoptosis of PMN and removal (e.g., by efferocytosis), (4) clearance of pathogens, inflammatory stimuli, and cell debris, and (5) tissue repair.

MФs are master cells in resolution since they have specialized functions, also mirrored by specific cellular and molecular phenotypes (Stables et al., 2011), that permit the clearance of pathogens, infiltrated leukocytes, or inflammatory debris and regulate the tissue remodeling or repair (Gordon, 2007). It is now evident that failure to resolve inflammation in a proper and timely manner preludes to pathology since the persistence of the phlogistic process can lead to tissue damage or systemic disease (Nathan and Ding, 2010). Therefore, what makes inflammation an "unwanted" process it is not how often or how extensive it starts, but how quickly and effectively it resolves.

\section{NON-RESOLVING AIRWAY INFLAMMATION IN CYSTIC FIBROSIS}

Unresolved acute inflammation and chronic infection, mainly due to $P$. aeruginosa, are key mechanisms responsible for progressive airways destruction in cystic fibrosis (CF), the most common hereditary human disease (Davis et al., 1996; Cantin et al., 2015). In CF patients, airway inflammation starts early in life, persists even in the absence of detectable microbial colonization, is exaggerated in magnitude compared to the burden of infection, and does not resolve (Table 1). Despite ground-breaking advances in CF therapies obtained with the discovery of drugs that correct or potentiate the defective $\mathrm{CF}$ transmembrane conductance regulator (CFTR) protein, the unrelenting inflammatory response in the airways and persistent, recurrent infections remain the principal cause of progressive lung disease in patients, contributing to the high morbidity and early mortality of CF, with $\sim 800$ life losses/year (Cystic Fibrosis Foundation, 2016; Zolin et al., 2017). Remarkably, current anti-inflammatories, like ibuprofen, that block the activation phase of inflammation by inhibiting cyclooxygenase (COX)-derived prostanoids have provided little clinical benefits to patients (Lands Larry and Stanojevic, 2013), suggesting that multiple factors contribute to airway inflammation in CF. Hence, different strategies must be explored, considering that the risk/ benefit ratio for anti-inflammatories in CF is particularly narrow since inflammation is required for restraining bacterial spread.

The unrelenting, non-resolving lung inflammation in CF patients is participated by a number of cells, stimuli, and cellular pathways (Figure 2). Although lung of neonates with $\mathrm{CF}$ is structurally normal, bronchiolar mucus plugging, inflammation, and hypertrophy of submucosal gland ducts are evident as early as few months of age even without detectable 
infections (Bedrossian et al., 1976; Stoltz et al., 2015). Once patients with CF are challenged by bacterial or viral infection, airway inflammation is disproportionate to the degree of infection, with a high PMN infiltration and large release of pro-inflammatory molecules, such as tumor necrosis factor (TNF)- $\alpha$, interleukin (IL)-8, 6, $1 \beta$ (Balough et al., 1995; Bonfield et al., 1995; Noah et al., 1997; Muhlebach et al., 1999; Tirouvanziam et al., 2000; Muhlebach and Noah, 2002), prostaglandins, and $\mathrm{LTB}_{4}$ (Konstan et al., 1993). More importantly, lung inflammation in CF appears incapable of removing pathogens effectively and never resolves (Roesch et al., 2018).

PMNs are the predominant leukocytes contributing to airway inflammation in CF. Once recruited at CF airway tissues, they play an important defense function by phagocytosing microorganisms, secreting antimicrobial peptides, and entrapping

TABLE 1 | Hallmarks of airway inflammation in patients with CF.

\section{Hallmarks of airway inflammation in CF}

1. Begins early in life
2. Is disproportionate to the degree of infection
3. Starts and/or persists even in the absence of infection
4. Never resolves

microbes in neutrophil extracellular traps (NETs), DNA meshes formed of released DNA and proteins. However, in CF, excessive and uncontrolled neutrophil infiltration and activity have pathologic consequences, with the release of proteolytic enzymes that can degrade extracellular membrane and tissues, oxidant species that can cause structural damages to the airways and further aliment inflammation, and NETs that increase mucus viscosity (Nichols and Chmiel, 2015).

Macrophages also contribute to the non-resolving inflammation in CF airways (Bruscia and Bonfield, 2016). Data indicate that $\mathrm{M} \Phi$ s of $\mathrm{CF}$ patients have a hyper-responsive phenotype, producing a high amount of inflammatory cytokines when exposed to bacterial stimuli (Bruscia et al., 2009, 2011). This abnormal response may arise to basic defects in CFTR or to the persistence in bacterial colonization. СF МФs also seem to have a defective ability to clear bacteria (possibly secondary to impaired acidification of phagosome due to CFTR dysfunction) (Di et al., 2006; Deriy et al., 2009; Del Porto et al., 2011), although this is not completely understood (Haggie and Verkman, 2007).

In addition to the well-known role in regulating vascular tone, blood fluidity, and hemostasis, platelets (PLTs) have important roles in innate immunity and inflammation. PLT can release nitric oxide (NO) and prostanoids that control leukocyte interactions

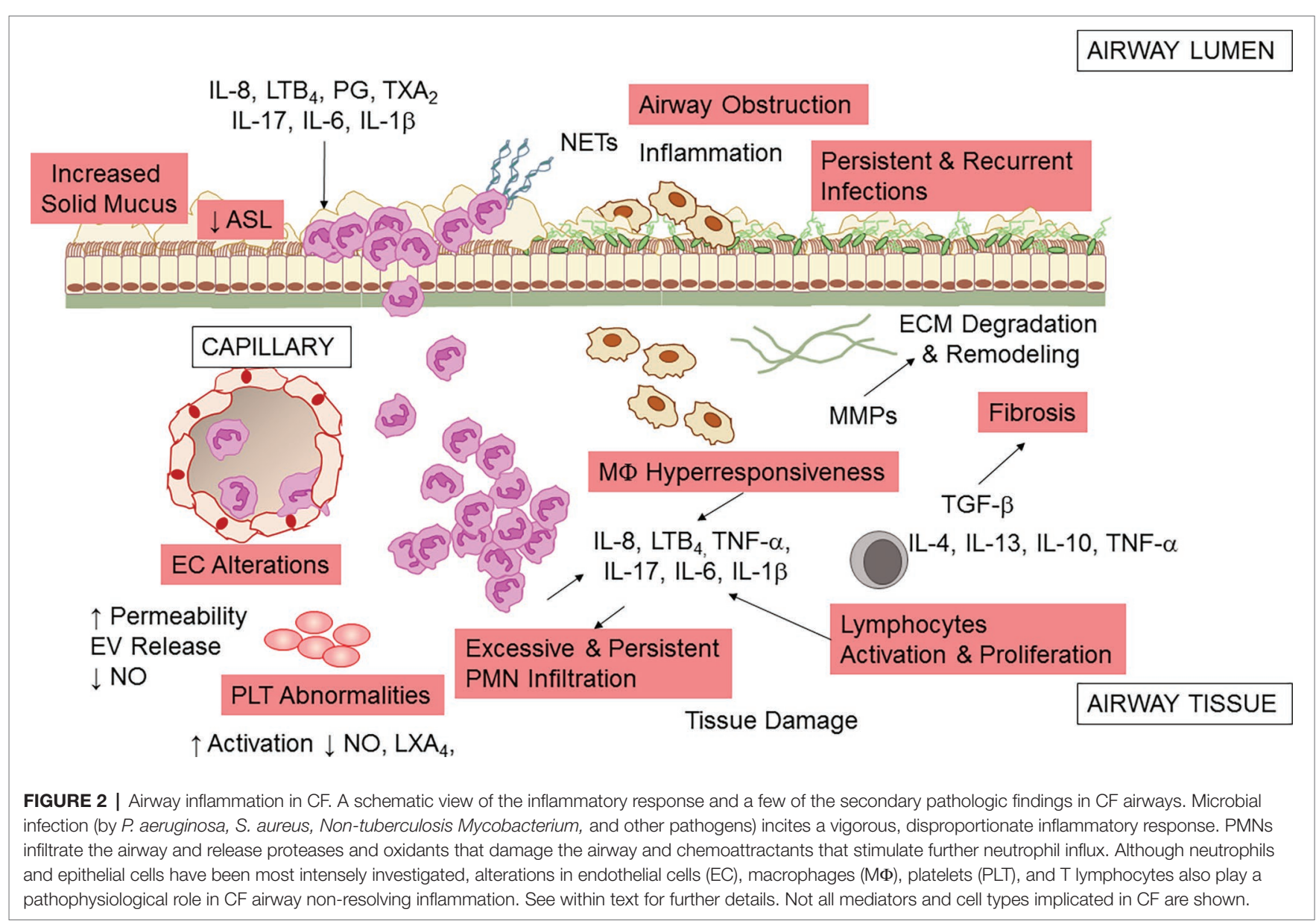


with endothelial cells (EC), respond to pathogens, and interact with blood leukocytes dictating their fate and functions (Rondina et al., 2013). Clinical-based and ex vivo evidence of increased PLT activation in CF has been documented, suggesting that these cells can contribute to inflammation in these patients (Ciabattoni et al., 2000; O’Sullivan et al., 2005; Lindberg et al., 2018) Moreover, PLTs are important effector of resolution, since they carry enzymes and substrates required for the biosynthesis of pro-resolving mediators. PLT interactions with PMN, a key process occurring during inflammation, lead to the formation of lipoxins (LX) $\mathrm{A}_{4}$ (Romano and Serhan, 1992; Romano et al., 1993), the first identified specialized pro-resolving lipid mediator (SPM) that stops inflammation and promotes return to homeostasis (Romano et al., 2015). A study from Mattoscio and coworkers demonstrated that defective CFTR function expressed at PLT surfaces decreases $\mathrm{LXA}_{4}$ formation by inhibiting PLT LX synthase activity (Mattoscio et al., 2010). In the same study, the authors also provided compelling evidence that PLTs isolated from volunteers with CF produce significantly less $\mathrm{NO}$ and have an increase pro-survival activity in PMN, thus prolonging the duration of inflammation (Mattoscio et al., 2010). Critical roles of PLT in inflammation and immunity have been recently confirmed in a preclinical model of $P$. aeruginosa lung infection (Amison et al., 2018), further underlining the involvement of these cells in CF lung inflammation.

Epithelial cells form the lining of airway tissues and are the first encounter of microbes and other toxins that activate the acute inflammatory reactions. CFTR is abundantly present on the apical side of airway epithelial cells (AECs), and the absence of a functional protein causes incomplete cAMPdependent $\mathrm{Cl}^{-}$and $\mathrm{HCO}_{3}{ }^{-}$secretion in airway. Therefore, mucus becomes dehydrated (Perez et al., 2006), mucins (main protein components of secretions) are tethered at apical AEC surfaces (Kreda et al., 2012; Mall, 2016; Livraghi-Butrico et al., 2017), and extracellular $\mathrm{pH}$ is decreased (McShane et al., 2003), thus impairing host antimicrobial defenses (see Cantin et al., 2015; Roesch et al., 2018 for a more complete review on this topic). Increased release inflammatory cytokines and chemokines through NF- $\kappa B$ and intracellular stress signals (e.g., $\mathrm{Ca}^{2+}$ ) have been largely documented in AEC isolated from CF patients (Weber et al., 2001; Perez et al., 2006; Hybiske et al., 2007) and can contribute to the non-resolving feature of inflammation in CF (Roesch et al., 2018).

Vascular endothelial cells (ECs) have pivotal roles in regulating inflammation, controlling the leakage of plasma proteins as well as leukocyte infiltration by releasing soluble mediators such as NO, IL-8, PG, and TX (Gimbrone, 1995). CFTR expression in EC and the involvement of CFTR in response to hypoxia have been documented (Tousson et al., 1998; Tabeling et al., 2015). In addition, clinical signs of EC dysfunctions in individuals with CF have been documented (Tousson et al., 1998; Romano et al., 2001; Poore et al., 2013). Recently, Totani and coworkers have shown that CFTR controls homeostatic functions of EC. In particular, CFTR blockade increased EC permeability and loss of membrane integrity under flow. Also, CFTR blockade suppressed NO generation and enhanced IL-8 release, possibly contributing to the sustained PMN recruitment in CF. Remarkably, in the same study, the authors showed that a combinatorial treatment with phosphodiesterase inhibitors and $\beta 2$ adrenergic receptor agonists corrected CFTR-dependent EC abnormalities providing novel cellular targets for treating inflammation in CF (Totani et al., 2017).

Many dysregulated $\mathrm{T}$ cell subsets and related cytokines have been identified in CF lung, including Th17 that can promote PMN influx by producing IL- 8 and IL-17, suggesting that T lymphocytes have important roles in lung inflammation in $\mathrm{CF}$ (Kushwah et al., 2013).

The introduction of CFTR correctors and potentiators allowed gaining of CFTR function in individuals carrying some mutations (Nick and Nichols, 2016; Donaldson et al., 2018). However, whether a better CFTR function translates into improvements in lung inflammation and infections is unclear. In a sub-study of the GOAL trial, Rowe and colleagues found a trend downward in abundance of CF pathogens such as Pseudomonas and Staphylococcus in the airways of study participants treated with ivacaftor, but no changes in inflammatory markers, including IL- $6,-8,-1 \beta$, and free elastase in sputum (Rowe et al., 2014; Heltshe et al., 2015). In a subsequent study, Hisert and colleagues found that $P$. aeruginosa abundance in subjects treated with ivacaftor declined during the first year of treatment but started to increase afterwards. Concentrations of sputum inflammatory markers were also reduced, even if still present in huge quantities at the end of the study (Hisert et al., 2017). It is conceivable that, as infection rebounds, inflammation will eventually follow.

Given the myriad of cellular, soluble, and intracellular players that can contribute to chronic inflammation in CF, an ideal antiinflammatory drug for these patients should target many component of this excessive inflammatory response and stimulate resolution.

\section{RESOLUTION OF INFLAMMATION IS AN ACTIVE PROCESS}

Pioneer work by Dr. Serhan and coworkers (see Serhan and Levy, 2018 for a recent review) and from many others worldwide (Savill et al., 1989a,b; Perretti et al., 2002; Perretti and Flower, 2004; Serhan et al., 2007) has demonstrated that resolution is an active process regulated by specific mediators (Perretti et al., 2015) and changed the traditional view of resolution. Endogenous SPMs produced from essential polyunsaturated fatty acids (PUFAs) stop excessive PMN infiltration, counter pro-inflammatory signals, and enhance the active clearance of pathogens and death cells by $М \Phi$. Collectively, SPMs accelerate the restitutio ad integrum; thus, they are often referred as "immunoresolvents" (Dalli et al., 2013a,b) or "agonists of resolution" (Schwab et al., 2007; Chiang et al., 2015). In addition to LX, the SPM genus includes E, D, and T series resolvins $(\mathrm{Rv})$, protectins $(\mathrm{PD})$, and maresins $(\mathrm{MaR})$ that are biosynthesized through transcellular routes involving both resident and blood cells by lipoxygenase (LO) enzymatic activity from arachidonic acid (AA), eicosapentaenoic acid (EPA), docosapentaenoic acid (DPA), or docosahexaenoic acid (DHA) available in inflammatory exudates (Figure 3; Kasuga et al., 2008). 


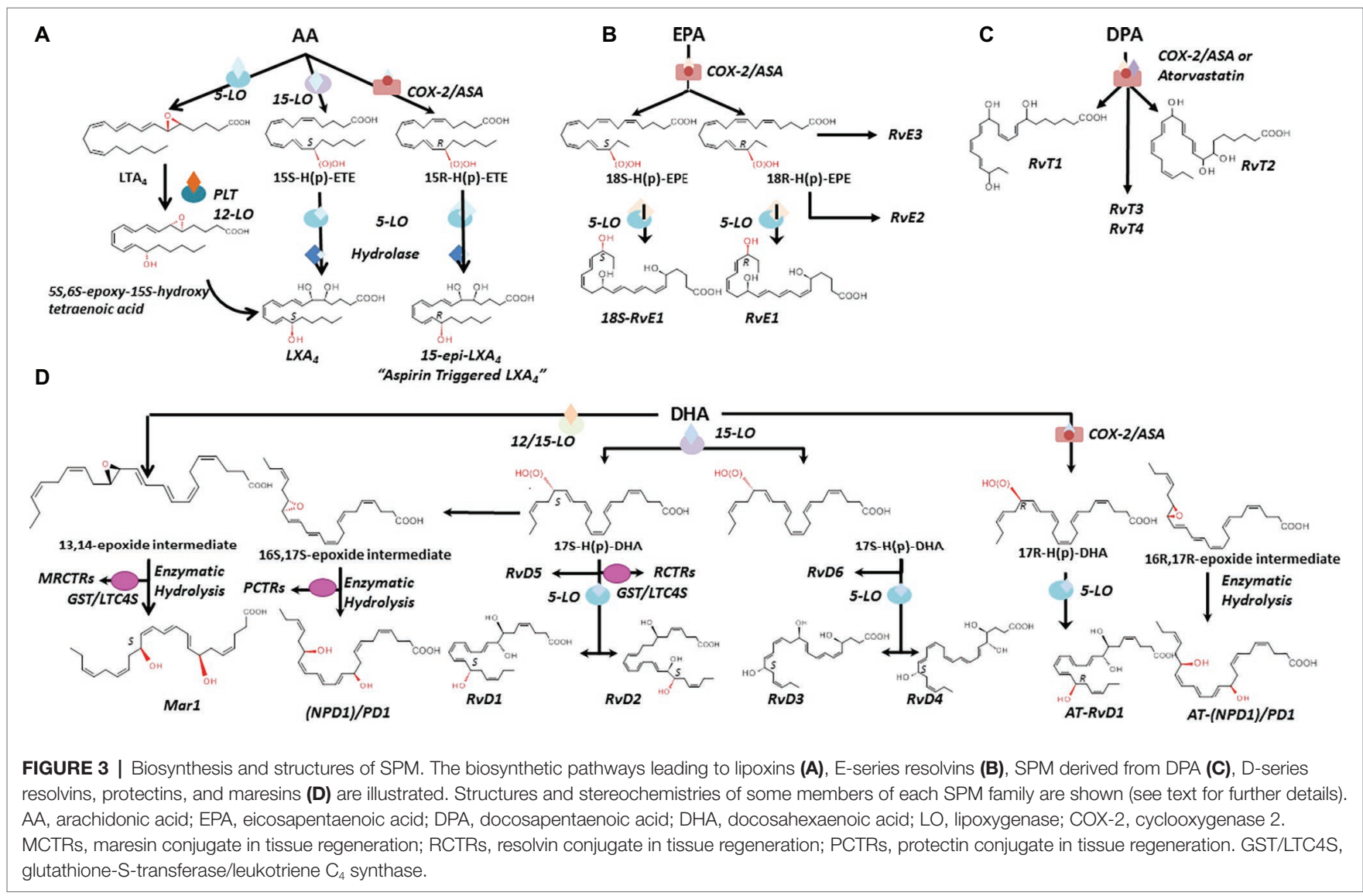

In human system, SPM can be found in biological specimens at pico- to nanogram levels, which are commensurate to their range of activity. SPMs are identifiable in blood (Psychogios et al., 2011; Mas et al., 2012; Colas et al., 2014; Barden et al., 2016; Dalli et al., 2017), breast milk (Weiss et al., 2013), breath condensate (Levy et al., 2007), sputum (Eickmeier et al., 2017), urine (Gangemi et al., 2003; Sasaki et al., 2015), and tears (English et al., 2017). Levels of SPM can vary in response to inflammatory stimuli (Edenius et al., 1990; Gangemi et al., 2012), vascular damage (Brezinski et al., 1992; Pillai et al., 2012), or physical exercise (Gangemi et al., 2003; Markworth et al., 2013). SPMs are also enriched in inflammatory exudates such as synovial fluids from volunteers with rheumatoid arthritis (Norling et al., 2016), skin blisters (Morris et al., 2009; Motwani et al., 2017, 2018), and bronchoalveolar lavage fluids (BALs) from patients with airway diseases (Lee et al., 1990; Karp et al., 2004; Planagumà et al., 2008; Ringholz et al., 2014). Of interest, accruing evidence indicates that SPM levels are often diminished in patients with a more severe disease, are unbalanced compared to pro-inflammatory eicosanoids, and inversely correlate with the clinical status. Several RvDs and Es, PD1, and Mar-1 are reduced in adipose tissue samples from obese subjects (Titos et al., 2016), and RvD1 is significantly lower in vulnerable areas of human atherosclerotic plaques (Fredman et al., 2016). $\mathrm{LXA}_{4}$ and $\mathrm{LXA}_{4}$ to $\mathrm{LTB}_{4}$ ratio are decreased in BAL from patients with CF (Karp et al., 2004; Ringholz et al., 2014). RvD1 levels are further reduced in CF patients with a worse pulmonary function (Eickmeier et al., 2017). Collectively, these studies suggest that reduced levels of SPM may contribute to the progression and worsening of human diseases.

Since resolution is an active process directed by selected mediators, the exploitation of these endogenous controllers of inflammation as therapeutics opened novel opportunities in pharmacology for the treatment of human diseases (Gilroy et al., 2004; Tang et al., 2012). For example, annexin (Anx) A1, an endogenous protein abundant in PMN granules, and melanocortins dampen inflammation and protect from tissue damage (Hecht et al., 2009; Montero-Melendez et al., 2014; Dalli et al., 2015a,b). Similarly, synthetic LX stable analogs showed anti-inflammatory and organ protective activities (Bannenberg et al., 2004; Guilford et al., 2004; Sun et al., 2009). Norling and coworkers proved the efficacy of D-series resolvins in ameliorating arthritis (Norling et al., 2016) and joint inflammation (Norling et al., 2016). AnxA1-enriched microvesicles derived from human PMN also convey anti-inflammatory, pro-resolution, and organ protective actions in experimental mandibular joint disease (Norling et al., 2011), arthritis (Headland et al., 2015), and atherosclerosis (Leoni et al., 2015). Recently, SPM proved to reduce inflammation in human volunteers undergoing UV-killed E. coli skin inflammation (Motwani et al., 2018) Hence, the exploration of pharmacological properties of SPM and other chemical mediators of endogenous resolution is of considerable interest (Perretti et al., 2015). 


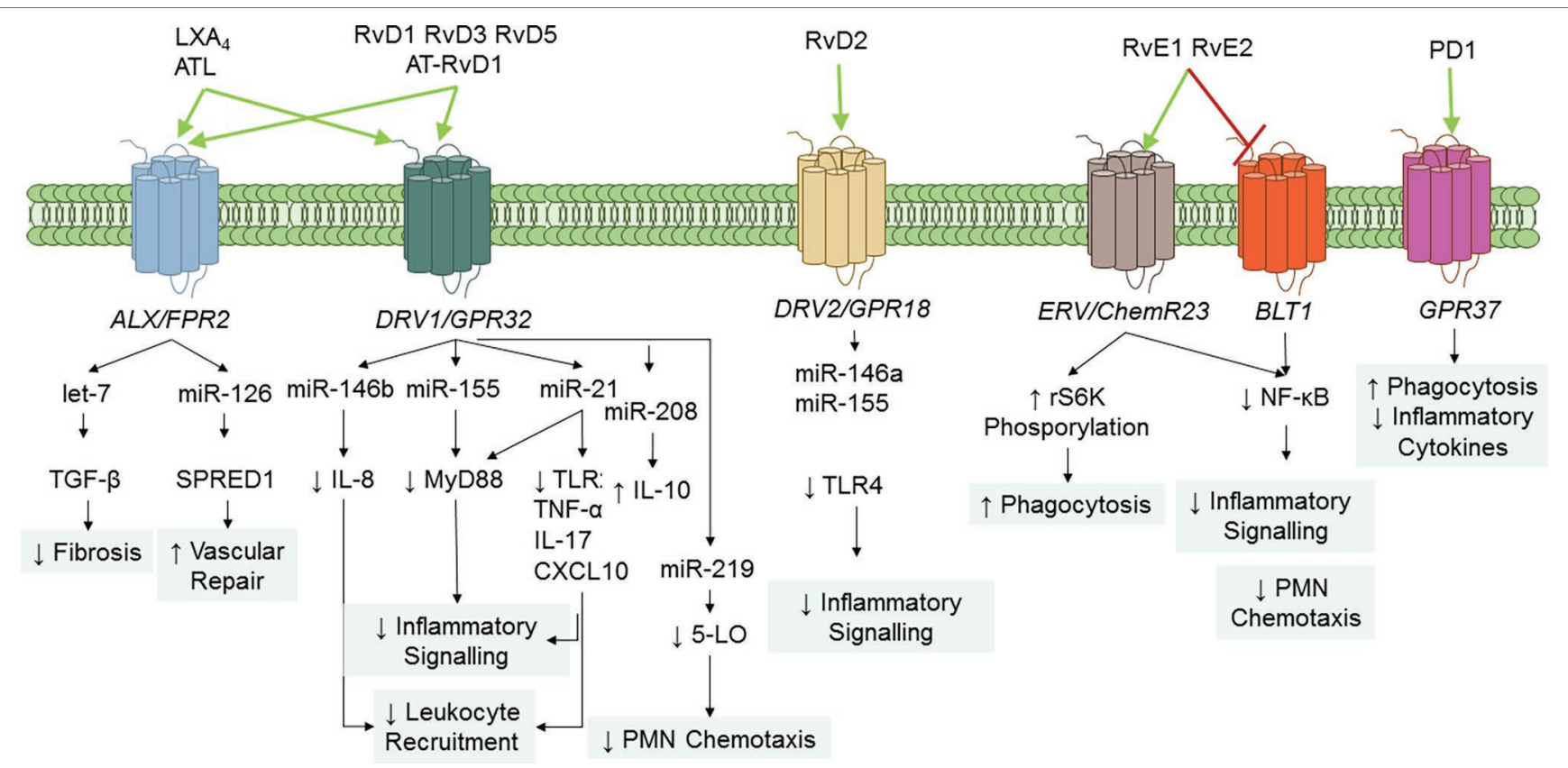

FIGURE 4 | SPM GPCR and signaling pathways. To date, five specific SPM GPCRs have been identified in human and murine cells: ALX/FPR2, DRV1/GPR32, ERV1/ChemR23, DRV2/GPR18, and GPR37. Binding of SPM to their GPCR regulates cell-specific signaling pathways that ultimately diminish inflammation and enhance resolution. RvE1 also serves as a partial antagonist on leukotriene (LT) $B_{4} B L T 1$ receptor to stop PMN infiltration.

In order to define resolution in an unbiased, quantitative manner, Bannenberg et al. defined mathematical "resolution indices" by determining the cellular changes in exudates during an experimental, acute inflammatory reaction (namely local peritonitis in mice induced by injection of zymosan A particles from S. cerevisiae, a Toll-like receptor activator) with a fixed “time zero." Resolution indices encompass: $T_{\max }$, i.e., time point of maximum PMN infiltration $\left(\Psi_{\max }\right) ; T_{50}$, time necessary to achieve $50 \%$ reduction in PMN number $\left(\Psi_{50}\right)$ from $\Psi_{\max }$; resolution interval $\left(R_{\mathrm{i}}=T_{50}-T_{\max }\right)$, time interval between $T_{\max }$ and $T_{50}$ (Bannenberg et al., 2005). Resolution indices have been largely used and employed in several preclinical models of inflammatory diseases for testing properties of endogenous chemical mediators or pharmacological agents (Schwab et al., 2007; Haworth et al., 2008; Navarro-Xavier et al., 2010).

\section{BIOSYNTHESIS OF SPM}

\section{AA Metabolome}

\section{Lipoxins and Aspirin-Triggered Lipoxins (ATL)}

LXs ("lipoxygenase interaction products") such as $\mathrm{LXA}_{4}$ and $\mathrm{B}_{4}$ are resulting from the enzymatic conversion of AA during cell-cell interactions (Serhan et al., 1984; Samuelsson et al., 1987). AA oxygenation by $15-\mathrm{LO}$ and 5-LO, followed by enzymatic hydrolysis of hydro(peroxy)-containing intermediates, results in the formation of $\mathrm{LXA}_{4}$ and $\mathrm{B}_{4}$ (Edenius et al., 1990; Levy et al., 1993; Gronert et al., 1998) and reviewed by Recchiuti et al., 2016. In blood, AA is converted into $\mathrm{LXA}_{4}$ and $\mathrm{B}_{4}$ by the sequential activity of 5-LO (present in leukocytes) and
12-LO (abundant in platelets) (Figure 3A; Serhan and Sheppard, 1990; Romano and Serhan, 1992). In vascular cells, acetylation of COX-2 by aspirin renders this enzyme capable of converting AA into 15R-HETE, which then serves as a substrate of leukocyte 5-LO for the biosynthesis of LX containing an OH-group in the $R$ configuration at C15 (Figure 3A; Claria and Serhan, 1995). These "aspirin-triggered" lipoxins (ATLs), also named 15-epi-LX, are produced in human subjects taking aspirin (Chiang et al., 2004), and mediate the anti-inflammatory actions of low-dose aspirin in healthy individuals (Morris et al., 2009). Of interest, studies from Birnbaum et al. demonstrated that atorvastatin, in addition to produce a lipid-lowering effect, promotes the generation of $15 R-\mathrm{LXA}_{4}$ via $S$-nitrosylation of COX-2 in myocardial cells (Birnbaum et al., 2006), whereas Gutierrez et al. showed that pioglitazone, an insulin-sensitizing agent, raises plasma levels of 15-epi-LXA (Gutierrez et al., 2012). Hence, aspirin, atorvastatin, and pioglitazone can activate the resolution process.

More recently, a study by Lee and coworkers revealed a new mechanism by which 15 -epi-LXA 4 biosynthesis can be activated in the nervous system. In their study, the authors found that sphingosine kinase 1 (a key enzyme that converts sphingosine into the bioactive lipid sphingosine-1-phosphate) acetylates neuronal COX-2 skewing the production of 15 -epi-LXA $\mathrm{LA}_{4}$ and other SPM, resulting in an increase in phagocytosis of A $\beta$-amyloid by microglial cells and improvement of Alzheimer's disease (AD)-like pathology in mice (Lee et al., 2018). Since sphingosine kinase 1 is reduced in human AD neurons (Lee et al., 2018) and several SPMs are diminished in cerebrospinal fluid from patients with AD (Nielsen et al., 2016; Zhu et al., 2016), this 
study provides a new framework for targeting resolution and $\mathrm{SPM}$ to dampen inflammation in $\mathrm{AD}$.

\section{EPA Metabolome \\ E-Series Resolvins}

RvE1 (5S,12R,18R-trihydoxy-6Z,8E,10E,14Z,16E-EPA) (Arita et al., 2005) is produced in endothelial cells by aspirin acetylated COX-2 that converts EPA into 18R-hydro(peroxy)eicosapentaenoic acid (HEPE), then metabolized by activated leukocytes (e.g., PMN) into RvE1 (Figure 3B). Interestingly, the $18 R$-HEPE isomer was dominant to its epimer $18 S$-HEPE in plasma from volunteers given EPA, while 18S-HEPE was increased by aspirin administration (Oh et al., 2011b). 18SHEPE can also be converted to RvE1 and RvE2 by 5-LO and $\mathrm{LTA}_{4}$ hydrolase (Oh et al., 2011a, 2012), and cytochrome P450 mediates the oxygenation of EPA into RvE1 (Serhan et al., 2000; Haas-Stapleton et al., 2007). RvE2 (5S,18dihydroxy-EPE) is produced via a reduction in 5S-hydroperoxy, 18-hydroxy-EPE (Tjonahen et al., 2006; Ogawa and Kobayashi, 2009; Oh et al., 2011a, 2012) in resolving exudates and in human whole blood, while $18 R$-RvE3 (17R,18R-dihydroxy$5 Z, 8 Z, 11 Z, 13 E, 15 \mathrm{E}-\mathrm{EPE})$ and epimeric $17 R, 18 S$-RvE3 are biosynthesized via 12/15-LO in eosinophils (Figure 3B; Isobe et al., 2012, 2013).

\section{DPA Metabolome}

EPA is not the only $\omega-3$ fatty acid present in mammalian cells. n-3 docosapentaenoic acid (7Z,10Z,13Z,16Z,19Z-docosapentaenoic acid; n-3 DPA) is an intermediate of EPA biosynthesis from its precursor alpha-linolenic acid (Calder, 2011). Using targeted lipid mediator metabololipidomics, Dalli and coworkers identified previously unrecognized SPM derived from DPA that are congenerous to D-series Rv, PD, and MaR. The new n-3 DPA molecules include 7,8,17-trihydroxy-9,11,13,15E,19Z-DPA (RvD1 $1_{n-3}$ DPA), 7,14-dihydroxy-8,10,12,16Z,19Z-DPA (MaR1 $\left.1_{\mathrm{n}-3 \mathrm{DPA}}\right)$ and related isomers MaR2 and $3_{\mathrm{n}-3 \mathrm{DPA}}$ (Dalli et al., 2013a), 10R,17S-dihydroxy7Z,11E,13E,15Z,19Z-DPA (PD1 ${ }_{\mathrm{n}-3 \mathrm{DPA}}$ ) (Dalli et al., 2013a; Aursnes et al., 2014), and 7S,17S-dihydroxy-8E,10Z,13Z,15E,19Z-DPA $\left(\right.$ RvD5 $\left._{\mathrm{n}-3 \mathrm{DPA}}\right)$ (Gobbetti et al., 2017). Structures of four new bioactive molecules derived from DPA and termed 13-series resolvins (RvT) were recently reported. RvTs carry a 13-carbon position alcohol, and their biosynthesis is dependent upon nitrosylation of COX-2 by atorvastatin (Figure 3C; Dalli et al., 2015a).

\section{D-Series Resolvins}

Earlier lipidomic studies of resolving exudates from mice administered DHA and aspirin identified DHA-derived molecules containing an OH-group at C17 (Serhan et al., 2002). By using isolated human cells and recombinant enzymes, Serhan and coworkers identified and recapitulated the entire biosynthetic pathways of D-series resolvins. Human endothelial cells exposed to hypoxia express highly amount COX-2 that converts DHA to 13-hydroxy-DHA or 17R-HDHA in the presence of aspirin. Both intermediates can be metabolized by human PMN to compounds termed "aspirin triggered" D-series resolvins (Serhan et al., 2002). By contrast, in the absence of aspirin, D-series resolvins with the $17 \mathrm{~S}-\mathrm{OH}$ group are predominant (Serhan et al., 2002; Hong et al., 2003). The complete organic synthesis and the stereochemistry of $17 S-, 17 R-R v D 1$, and $\mathrm{RvD} 2$ have been established as follows: $7 S, 8 R, 17 S$-trihydroxy-4Z,9E,11E,13Z,15E,19Zdocosahexaenoic acid (17S-RvD1), 7S,8R,17R-trihydroxy$4 Z, 9 E, 11 E, 13 Z, 15 E, 19 Z$-docosahexaenoic acid (17R-RvD1) (Sun et al., 2007), and 7S, 16R, 17S-trihydroxy-4Z, 8E, 10Z, 12E, 14E, 19Z-docosahexaenoic acid (RvD2) (Spite et al., 2009).

Additional members of this family have been identified: RvD3 (4S,11R,17S-trihydroxy-5Z,7E,9E,13Z,15E,19Z-DHA) (Dalli et al., 2013b), RvD4 (4S,5R,17S-trihydroxy-6E,8E,10E,13E,15Z, 19Z-DHA) (Winkler et al., 2018), RvD5 (7S,17S-dihydroxy$4 Z, 8 E, 10 Z, 13 Z, 15 E, 19 Z$-DHA), and RvD6 (4S,17S-dihydroxy$5 E, 7 Z, 10 Z, 13 Z, 15 E, 19 Z-D H A)$.

\section{(Neuro)Protectins}

Although PD1(10R,17S-dihydroxy-docosa-4Z,7Z,11E,13E,15Z,19Zhexaenoic acid) (Serhan et al., 2006) is the founding member of this family, several isomers that also possess lower bioactivity than PD1 have also been identified: 10S,17S-diHDHA, 4S,17SdiHDHA, 7S,17S-diHDHA, and 22-hydrox-10,17S-docosatriene (Serhan et al., 2002; Hong et al., 2003), and an aspirin PD1 has been reported (Marcheselli et al., 2003) (10R,17R-dihydroxydocosa-4Z,7Z,11E,13E,15Z,19Z-hexaenoic acid) (Figure 3D).

\section{Maresins}

Maresins (from macrophage mediator in resolving inflammation) are a fourth family of DHA-derived SPM (Ishida et al., 2009). The structural elucidation, complete biochemistry assignment, and total organic synthesis of two members of this family have been reported. Mar-1 (7R,14S-dihydroxy-4Z,8E,10E,12Z, $16 Z, 19 Z$-DHA) and Mar-2 (13R,14S-dihydroxy-4Z,7Z,9E,11Z,1 $6 Z, 19 Z$-DHA) are produced in tissues by $M \Phi$ and in the vasculature during PLT-PMN crosstalk through the action of 12-LO (Serhan et al., 2009; Dalli et al., 2013c; Abdulnour et al., 2014; Deng et al., 2014). In vivo and in vitro they promote resolution by increasing efferocytosis, skewing $M \Phi$ pro-resolutive phenotypes, and inhibiting PMN infiltration. They also hold organ protective and tissue-regenerative actions (Serhan et al., 2012). Mar-1 and Mar-2 receptors have not been identified yet.

\section{Cysteinyl-Conjugated SPM}

Lipidometabolomic profiling of murine exudates, spleens, and human fluids (including blood and breast milk) has revealed new families of SPM covalently bond to cysteine residues, collectively named SPM "conjugated in tissue regeneration" (CTR).

DHA is converted by 12-LO into 13,14-epoxy-Maresin (an intermediate of Mar-1 and Mar-2) that can be directly conjugated at C13 to glutathione by LTC4 Synthase, yielding maresin conjugated in tissue regeneration 1 (MCTR 1;13R-glutathionyl, 14S-hydroxy$4 Z, 7 Z, 9 E, 11 E, 13 R, 14 S, 16 Z, 19 Z-\mathrm{DHA})$, the first identified cysteinylSPM. Subsequent cleavage of Glu and Gly residues converts MCTR1 into MCTR2 (13R-cysteinylglycyl, 14S-hydroxy-4Z,7Z, 9E,11E,13R,14S,16Z,19Z-DHA), and MCRT3 (13R-cysteinyl, 14S-hydroxy-4Z,7Z,9E,11E,13R,14S,16Z,19Z-DHA) (Rodriguez and Spur, 2015a). MCTRs accelerate tissue regeneration in planaria, 
reduce neutrophil infiltration during E. coli peritonitis, and stimulate bacterial phagocytosis by MФ (Dalli et al., 2014, 2016a,b). They also antagonize $\mathrm{LTD}_{4}$ binding to recombinant cysLT receptor 1 and actions in vascular cells (i.e., induction of leakage) and intact hearts (i.e., lowering of heartbeats) (Chiang et al., 2018).

Mouse and human leukocytes convert $17 \mathrm{H}(\mathrm{p})$ DHA into distinct sets of sulfide-conjugated resolvins and protectins (Dalli et al., 2015b). Attachment of glutathione at the 7,8-epoxide intermediate of $\mathrm{RvD}$ generates resolvin conjugate in tissue regeneration 1 (RCTR1, 8R-glutathionyl-7S,17S-dihydroxy-4Z,9E, $11 E, 13 Z, 15 E, 19 Z-D H A)$ that is in turn cleaved into RCTR2 (8R-cysteinylglycinyl-7S,17S-dihydroxy-4Z,9E,11E,13Z,15E,19ZDHA) by $\gamma$-glutamyltranspeptidase and into RCTR3 (8R-cysteinyl7S,17S-dihydroxy-4Z,9E,11E,13Z,15E,19Z-DHA) via peptidases (Rodriguez and Spur, 2017; de la Rosa et al., 2018). RCTRs stimulate tissue repair in vivo, enhance $\mathrm{M} \Phi$ phagocytosis, and reduce cytokines and PMN recruitment in vivo and in vitro (de la Rosa et al., 2018).

Binding of glutathione at $\mathrm{C} 16$ of $17 \mathrm{H}(\mathrm{p}) \mathrm{DHA}$ produces protectin conjugated in tissue regeneration 1 (PCTR1, 16R-glutathionyl$4 Z, 7 Z, 10 Z, 12 E, 14 E, 16 R, 17 S, 19 Z-D H A)$ that is converted into PCRT2 (16R-cysteinylglycinyl-4Z,7Z,10Z,12E,14E,16R,17S,19Z-DHA) and PCRT3 (16R-cysteinyl-4Z,7Z,10Z,12E,14E,16R,17S,19Z-DHA) (Rodriguez and Spur, 2015b; Ramon et al., 2016). In addition to the name giving tissue regenerative actions, PCTRs possess immune-regulatory actions on innate lymphoid cells during bacterial infection in vivo (Dalli et al., 2017).

\section{SPM RECEPTORS AND INTRACELLULAR SIGNALING}

SPMs serve principally as ligand agonists to cognate GPCRs to exert cell-specific actions that broadly regulate inflammation and resolution (Figure 4). Studies from Nigam et al. first demonstrated that $\mathrm{LXA}_{4}$ stimulates lipid remodeling and release of AA in PMN in a pertussis toxin-sensitive manner (Nigam et al., 1990). Fiore et al. provided the first evidence for stereoselective, specific, and reversible binding of $\mathrm{LXA}_{4}$ to human PMN (with a $K_{\mathrm{d}} \sim 0.5 \mathrm{nM}$ ), thus confirming the role of GPCR receptor(s) in conveying bioactions of $\mathrm{LXA}_{4}$ (Fiore et al., 1992). Subsequently, formyl peptide receptor like-1 was identified as $\mathrm{LXA}_{4}$-GPCR in a human neutrophil cell line (Fiore et al., 1994). This receptor has been formerly renamed ALX/FPR2 in light of its affinity for $\mathrm{LXA}_{4}$ (Ye et al., 2009). ALX/FPR2 is abundantly present in myeloid cells, lymphocytes, dendritic cells, and resident cells (Chiang et al., 2006). Orthologs the human ALX/FPR2 gene have been sequenced in rodents (Takano et al., 1997; Chiang et al., 2003). In addition to $\mathrm{LXA}_{4}$ and ATL, ALX/FPR2 is activated by AnxA1 and its N-terminal peptides bind and activate ALX/FPR2 (Perretti et al., 2002), which is the archetype of GPCR conveying both lipid and peptide pro-resolving mediators. Of interest, $\mathrm{LXA}_{4}$ also functions as modulator of cannabinoid receptor CB1 (Pamplona et al., 2012), which may contribute to the anti-nociceptive activities of this SPM (Svensson et al., 2007; Abdelmoaty et al., 2013). In addition, earlier studies demonstrated that 15-epi-LXA ${ }_{4}$ also binds at cysteinyl
LT receptor 1 (CysLT1) with equal affinity to $\mathrm{LTD}_{4}$, providing further evidence for ATL in dampering CysLT signals in the vasculature (Gronert et al., 2001). Gain and loss-of-function approaches of ALX/FPR2 in human cells and in mice proved its essential role in mediating LX activities. Indeed, targeted overexpression of human ALX/FPR2 in murine myeloid cells increased the sensitivity to $\mathrm{LXA}_{4}$ stable analog, left-shifting the dose-response curve (Devchand et al., 2003). On the contrary, ALX/FPR2 nullified mice have an unrelenting inflammatory response, defective resolution, and lack of response to receptor ligands (Dufton et al., 2010; Krishnamoorthy et al., 2012; Norling et al., 2012). Pivotal roles of ALX/FPR2 in regulating inflammation and resolution have also been unveiled in humans. Indeed, the amounts of ATL and ALX/FPR2 expression drive magnitude and duration of the acute inflammatory response in human volunteers undergoing experimental inflammation (Morris et al., 2010). Hence, levels of ALX/FPR2 protein in tissues are fundamental to dictate the outcome of inflammation and its resolution. In this regard, Simiele et al. $(2012,2016)$ and Pierdomenico et al. (2015) recognized molecular basis of ALX/FPR2 transcription, identifying the core promoter sequence, transcription factors, and epigenetic mechanisms (including microRNAs) able to control ALX/FPR2 expression, and an inheritable human SNP that weakens promoter.

Arita et al. reported that RvE1 bound with high affinity $\left(K_{\mathrm{d}}=11.3 \pm 5.4 \mathrm{nM}\right)$ and stereoselectivity to cells overexpressing the GPCR ChemR23 (formerly known as chemerin receptor) (Arita et al., 2005) and human PMN membranes $\left(K_{d} \sim 50 \mathrm{nM}\right)$. Interestingly, binding to PMN was displaced by homoligand RvE1 $\mathrm{LTB}_{4}$, and U-75302 (a selective $\mathrm{LTB}_{4}$ receptor 1 antagonist) (Arita et al., 2007), indicating that RvE1 binding sites on human PMN are distinct from ChemR23. Lately, direct evidence for ligandreceptor interactions of $\mathrm{RvE} 1$ and its epimer $18 \mathrm{~S}-\mathrm{RvE} 1$ was reported using ChemR23 and BLT-1 $\beta$-arrestin cells with EC50 ( $6.3 \mathrm{pM})$ lower than that obtained with RvE1. In addition, the synthetic human chemerin-derived peptide (YHSFFFPGQFAFS), described as ligand for this same receptor (Wittamer et al., 2003), displaced $\left[{ }^{3} \mathrm{H}\right]-\mathrm{RvE} 1$ binding, indicating that $\mathrm{RvE} 1$ and chemerin share binding sites on ChemR23 (Arita et al., 2005; Hasturk et al., 2006). 18S-RvE1 also antagonized $\mathrm{LTB}_{4}$-mediated BLT1 activation in BLT-1 $\beta$-arrestin assays (Oh et al., 2011b). Hence, these results indicate that RvE1 and $18 S-\operatorname{RvE} 1$ share the same site(s) of binding to human ChemR23 and BLT-1.

RvE2 exerts potent and cell-specific actions on leukocytes (Tjonahen et al., 2006; Oh et al., 2012) and binds to human PMN, ChemR23- and BLT-1 $\beta$-arrestin cells, with similar affinity to RvE1, indicating that these two SPMs partially share receptors (Oh et al., 2012).

Krishnamoorthy et al. (2010) reported the identification of RvD1 receptors in human phagocytes. In their study, RvD1 reduced actin polymerization in human $\mathrm{PMN}$ in a pertussis toxin sensitive manner, did not activate $\mathrm{Ca}^{2+}$ release, nor induced cAMP formation in human PMN. In addition, $\left[{ }^{3} \mathrm{H}\right]-\mathrm{RvD} 1$ selectively bound to human PMN and monocytes with high affinity $\left(K_{\mathrm{d}} \sim 0.17 \mathrm{nM}\right)$ and was displaced $\mathrm{LXA}_{4}(\sim 60 \%)$, homoligand RvD1 ( 100\%), but not an AnxA1-derived peptide (Krishnamoorthy et al., 2010). Screening of a panel of GPCR 
established that RvD1 stopped NF- $\kappa B$ activation in cells overexpressing ALX/FPR2 or GPR32, but not other GPCRs (e.g., BLT1, BLT2, FPR, GPR-1, ChemR23, and CB1) treated with TNF- $\alpha$. Moreover, RvD1 activated ALX/FPR2 and GPR32 in recombinant $\beta$-arrestin cells as did AT-RvD1, RvD1-carboxymethyl ester, and a metabolically stable analog 17 (R/S)-methyl RvD1-ME (Krishnamoorthy et al., 2010). Hence, renaming GPR32 as DRV1 receptor following the International Union of Basic and Clinical Pharmacology (IUPHAR) nomenclature has been proposed (Alexander et al., 2017).

Experiments using genetically modified mice, receptor antagonists, or blocking antibodies confirmed that ALX/FPR2 and GPR32 mediate the RvD1 immunoresolving actions (Krishnamoorthy et al., 2010; Gavins et al., 2011; Hellmann et al., 2011; Recchiuti et al., 2011; Tang et al., 2012; Barnig et al., 2013; Buchanan et al., 2013; Lee and Surh, 2013; Norling et al., 2016), that encompass modification of transcription factors, microRNAs, and genes (Recchiuti et al., 2014). Human GPR32 is mostly expressed not only on PMN, monocytes, and $\mathrm{M} \phi$, but also on vascular endothelial cells (Krishnamoorthy et al., 2010). The murine ortholog of GPR32 is still unidentified, whereas it has been recently described in chimpanzees. Molecular circuits regulating GPR32 expression are unknown, while those of ALX/FPR2 have been reported and described (Simiele et al., 2012; Pierdomenico et al., 2015; Simiele et al., 2016).

Specific receptors for RvD3 and RvD4 have not yet been recognized. However, RvD3 and AT-RvD3 both stimulate GPR32, which contributes to their pro-resolving activities (i.e., stimulation of $\mathrm{M} \phi$ phagocytosis) (Dalli et al., 2013b). Finally, Chiang et al. also demonstrated GPR32 activation by RvD5 (Chiang et al., 2012).

Earlier studies demonstrated that RvD2 biactions were inhibited by petussis toxin (Spite et al., 2009), suggesting association with GPCRs. Chiang et al. identified the GPCR GPR18 as a RvD2 receptor in human leukocytes by using $\beta$-arrestin cell screening, binding of $\left[{ }^{3} \mathrm{H}\right]-\mathrm{RvD} 2$ to recombinant GPR18, and genetic manipulation of this receptor (Chiang et al., 2015, 2017). Based on these findings, GPR18 has been renamed as DRV2 following the IUPHAR guidelines.

Tritium-labeled PD1 binding was demonstrated in retinal pigment cells (RPEs) and human PMN (Kd $30 \mathrm{pmol} / \mathrm{mg}$ protein). Also, cold PD1 showed almost complete displacement of radio-labeled PD1, while other related omega-3 fatty acid compounds gave minimal or no displacement (Marcheselli et al., 2010). Recently, Bang et al. (2018) reported that PD1 binds with high affinity to HEK293 cells transfected with GPR37, a GPCR also known as parkin-associated endothelin-like receptor highly abundant in the brain. PD1 elicited $\mathrm{Ca}^{2+}$ increase in GPR37expressing cells and peritoneal MФs. The authors also found that GPR37 was required for conveying PD1 actions, like enhancement of phagocytosis. Hence, GPR37 is, bona fide, a PD1 receptor. Of interest, peptide (TX14) derived from prosaposin (a neurotrophic and myelinotrophic protein) shares binding to GPR37 and intracellular signaling with PD1, suggesting that this receptor, similarly to ALX and ChemR23, can mediate pro-resolution actions of both lipid and peptide ligands.
SPM interactions with their SPM regulate several intracellular mechanisms involved in inflammation. RvD1, RvD2, and RvE1 decrease NF- $\kappa \mathrm{B}$ activation, nuclear translocation, and cytokine production (Arita et al., 2005; Eickmeier et al., 2013; Chiang et al., 2017). RvE1 also signals the phosphorylation of the Akt-dependent ribosomal S6 kinase, which in turns stimulates MФ phagocytosis (Ohira et al., 2010). Pioneer studies from Recchiuti et al. (2011), demonstrated the role of microRNAs in mediating SPM actions in resolution circuits. In murine exudate leukocytes from zymosan-induced peritonitis, RvD1 regulates miR-21, miR-146b, miR-208a, and miR-219 in a time- and GPCRdependent manner. Identified target genes of these microRNAs include IL-8, IL-10, and 5-LO that have pivotal roles in acute inflammation (Recchiuti et al., 2011; Krishnamoorthy et al., 2012). In lung $\mathrm{M} \Phi$ sorted from mouse lungs during $P$. aeruginosa chronic infection, RvD1 increased levels of miR-155 and miR-21 controls Toll-like receptor (TLR) expression and downstream proteins (e.g., MyD88), thus dampening signaling in $M \Phi$ that can fuel persistent inflammation (Codagnone et al., 2018). In MФ infected with $E$. coli, RvD1 dampens the expression of pro-inflammatory genes such as COX-2 (Chiang et al., 2012) and, along with $\mathrm{LXA}_{4}$ and $17 R-R v D 1$, reduces cytokine production by $M \Phi$ induced by endotoxins (Merched et al., 2008). Of interest, RvD2 also decreases the expression of TLR4, MyD88, and other accessory proteins in human monocytes, and these actions were partially due to the upregulation of miR-146a (Croasdell et al., 2016). Therefore, regulations of $\mathrm{M} \Phi$ responses via microRNAs, NF- $\mathrm{BB}$, and TLR are a common mechanism of action of SPM.

SPMs are organ protective in experimental inflammation. $\mathrm{LXA}_{4}$ reduces kidney fibrosis and attenuates production of proteins stimulating fibrosis (e.g., fibronectin, N-cadherin, and thrombospondin) by upregulating microRNA let-7c and suppressing transforming growth factor (TGF)- $\beta$ (Brennan et al., 2013). In human EC, $\mathrm{LXA}_{4}$ increases the release of extracellular vesicles enriched of miR-126-5p, which, upon uptake by neighbor cells, diminishes sprouty-related EVH1 domain containing one protein and enhances wound healing (Codagnone et al., 2017). More recently, Mattè et al. found that oral administration of $17 R-R v D 1$ in humanized sickle cell mice exposed to hypoxia/ reoxygenation stress gave a marked increase in miR-126 and let-7 in lungs and kidneys, resulting in protection from inflammation-driven organ damage. Of interest, in the same model, $17 R-\mathrm{RvD} 1$ reduces activation of $\mathrm{Nrf}-2$, a pivotal intracellular protein involved in chronic inflammation, and stimulates clearance of apoptotic PMN and damaged erythrocytes by MФ (Matte et al., 2019). Hence, SPMs act on multiple cellular pathways to stop further inflammation, protect from tissue damage, and stimulate pro-resolutive functions of $М \Phi$.

\section{ROLES AND ACTIONS OF SPM IN CF}

Several studies demonstrate that the ability of the CF lung to resolve inflammation is defective, thus contributing to the pathophysiology and progression of lung damage in patients. A study from Karp and colleagues found lower amounts of $\mathrm{LXA}_{4}$ 
in BAL of CF children as compared to non-CF pediatric patients with other respiratory infections (Karp et al., 2004), and these findings were further corroborated by Ringholz et al. (2014). Along these lines, Mattoscio and coworkers demonstrated that CFTR defects dampen $\mathrm{LXA}_{4}$ production during PLT:PMN interaction (Mattoscio et al., 2010). Based on these observations, acebilustat (CTX-4430), an oral inhibitor of $\mathrm{LTA}_{4}$ hydrolase, that prevents $\mathrm{LTB}_{4}$ biosynthesis has been tested in phase I and II clinical trials with volunteers with $\mathrm{CF}$ with the hypothesis that this compound could shut down $\mathrm{LTB}_{4}$ and turn on $\mathrm{LXA}_{4}$ biosynthesis. Adult with mild-to-moderate $\mathrm{CF}$ symptoms treated with acebilustat had a significant reduction in sputum PMN numbers and neutrophil elastase levels (Elborn et al., 2017). A larger phase II trial has been completed with the purpose of identifying the optimal patient population, dose, duration, and endpoints for future acebilustat trials and understanding the drug's efficacy in patients with CF (Elborn et al., 2018).

Observation of defective SPM biosynthesis and downstream pathways in patients with CF have provided the framework for testing new anti-inflammatory drugs that work by augmenting pro-resolving mediators. Lenabasum (JBT-101) is an oral agonist of cannabinoid $\mathrm{CB} 2$ receptor on leukocytes that trigger the biosynthesis of $\mathrm{LXA}_{4}$ that resolves experimental inflammation in mice (Zurier et al., 2009). A phase IIa clinical trial of lenabasum recently completed in CF (Chmiel et al., 2017). At the end of the study, volunteers in the lenabasum arm showed a significant reduction in IL-8 and a trend downward reduced sputum neutrophil, elastase, and $\operatorname{IgG}$ compared to baseline. There was also a trend toward reduced risk of pulmonary exacerbations. Interestingly, recent results from Motwani et al. demonstrate that lenabasum carries potent anti-inflammatory and pro-resolving action in humans undergoing UV-killed E. coli skin injection (Motwani et al., 2017). In this study, lenabasum significantly reduced PMN numbers and pro-inflammatory prostanoids in exudates, whereas it increased levels of select SPM including RvD1 and $\mathrm{LXA}_{4}$. A multicenter phase IIb trial with volunteers 12 year of age or older in underway (NCT03451045).

Reduced 15-LO expression in nasal epithelial cells from CF patients has also been demonstrated (Jeanson et al., 2014). The exact molecular link between CFTR dysfunction and altered LO expression and/or activity remains of interest. It has also been reported that patients with CF have an unbalance between AA and DHA levels in plasma and cells (Kuo et al., 1962; Underwood et al., 1972; Gilljam et al., 1986; Freedman et al., 2004), which has prompted several studies aimed at restoring DHA levels with dietary supplementation of this omega-3 to patients (Elliott, 1976). Recently, works from Pierdomenico et al. (2017) demonstrate increased levels of the miR-181b in MФ and epithelial cells from airways of CF individuals. Increased miR-181b leads to a reduction in ALX/FPR2 expression and blunts the ability of $\mathrm{LXA}_{4}$ and RvD1 to enhance bacterial clearance and epithelial integrity (Pierdomenico et al., 2017). In another study, Bensalem and coworkers found that AnxA1 was diminished in intestine from $\mathrm{CFTR}^{--}$mice and nasal epithelial cells isolated from volunteers with CF (Bensalem et al., 2005). Also, inhibition of CFTR provokes an augmented inflammatory reaction in mice upon peritoneal injection of zymosan and delayed resolution related with reduced AnxA1 expression in peritoneal exudate leukocytes (Dalli et al., 2010). Thus, when resolution mechanisms are compromised, chronic inflammation will eventually ensue. Along these lines, restoration of AnxA1 levels with the recombinant protein corrected the overzealous inflammatory response seen with CFTR inhibition (Dalli et al., 2010).

Recent evidence signifies that SPMs convey protective biological activities to oppose excessive inflammation and tissue damage and to promote active return to homeostasis. During chronic $P$. aeruginosa infection in mice, RvD1 reduces PMN influx, dampens bacterial load, and ameliorates clinical sign of pathology. In addition, $\mathrm{RvD} 1$ also encourages $P$. aeruginosa clearance by human $\mathrm{M} \Phi$ and $\mathrm{PMN}$ and in vivo shortened the time required to resolve inflammation. Of note, RvD1 showed comparable effects to ciprofloxacin treatment (the reference antibiotic lung exacerbation treatment in CF patients) in reducing both bacterial titer and leukocyte infiltration and demonstrated additional benefits to mono antibiotic therapy. Several cytokines and chemokines that are increased in CF airways were also diminished in mice bearing chronic $P$. aeruginosa infection by $\mathrm{RvD} 1$ treatment, including IL-8, IL-1 $\beta$, and IL-17. RvD1 also exhibits pro-resolutive and protective actions in lung tissue since it strikingly lowers mucus metaplasia, parenchymal inflammation, and leukocyte infiltration in long-term infected $P$. aeruginosa mice (Codagnone et al., 2018). Consistently, $\mathrm{LXA}_{4}$ stable analog reduces neutrophil recruitment and bacterial burden in short-term $P$. aeruginosa murine models of lung infection (Karp et al., 2004). Along these lines, RvD2 reduces polymicrobial sepsis severity in mice (Spite et al., 2009), RvD1 diminishes inflammation in pneumonia triggered by viral and bacterial co-infection (Wang et al., 2017), whereas MaR1 and RvD3 enhance E. coli phagocytosis by M $\Phi$ (Colas et al., 2016). Therefore, confining excessive inflammation and boosting host defense against pathogens are crucial SPM bioactions during resolution.

Many of actions exerted by SPM to limit inflammation and infection were also recapitulated with isolated human cells, such as the ability to enhance phagocytosis of bacteria by leukocytes (Chiang et al., 2012; Colas et al., 2014; Pierdomenico et al., 2017; Codagnone et al., 2018). In addition, SPMs skew MФ from a pro-inflammatory to a pro-resolutive phenotype (Dalli and Serhan, 2012; Recchiuti et al., 2014; Pistorius et al., 2018), for instance, enhancing the expression on $М \Phi$ of surface receptors involved in the uptake of apoptotic cells (Matte et al., 2019).

SPMs target epithelial cells to regulate ion transport. $\mathrm{LXA}_{4}$ enhances CFTR-independent $\mathrm{Cl}^{-}$efflux from $\mathrm{CF}$ bronchial epithelial cells and inhibits $\mathrm{Na}^{+}$reabsorption, thus restoring the airway surface hydration (ASL) that is important for mucociliary clearance (Verriere et al., 2012; Al-Alawi et al., 2014; Higgins et al., 2016; Ringholz et al., 2018). RvD1 also enhances ASL height in human CF bronchial cells by reducing an amiloride-sensitive $\mathrm{Na}^{+}$channel (Ringholz et al., 2018). In airway epithelia exposed to bacterial infection in vitro, $\mathrm{LXA}_{4}$ and RvD1 proved to protect from cell injury, strengthen tight junction integrity, and reduce IL-8 production (Grumbach et al., 2009; Higgins et al., 2016; Ringholz et al., 2018). 
SPMs counter inflammatory responses occurring in the vasculature. RvD1 reduces IL- $1 \beta$-induced vascular permeability of EC and edema formation in lungs (Codagnone et al., 2018) and limits PMN adhesion on EC and diapedesis (Sun et al., 2007; Norling et al., 2012), $\mathrm{LXA}_{4}$ and RvD2 stimulate NO production that stops leukocyte interactions with EC (Paul-Clark et al., 2004; Spite et al., 2009). $\mathrm{LXA}_{4}$ and $\mathrm{B}_{4}$ counter $\mathrm{LTB}_{4}$-induced PMN migration (Papayianni et al., 1996), while RvE1 among SPM has the unique property of diminishing the number of PLT:leukocyte aggregates in human whole blood (Dona et al., 2008) and ADP-induced PLT aggregation and activation (Fredman et al., 2010), which are enhanced in patients with CF.

Emerging evidence signifies now that SPMs are safe and effective in treating inflammatory diseases in humans. A small clinical trial with infants with eczema showed that topical application of a $\mathrm{LXA}_{4}$ stable analog was as potent as mometasone furoate in reducing disease severity, eczema area, and clinical scores, improving the quality of life of patients ( $\mathrm{Wu}$ et al., 2013). More recently, Kong and colleagues reported that $\mathrm{LXA}_{4}$ methyl ester was superior to corticosteroids in improving lung function of children with asthma and was well tolerated (Kong et al., 2017). Finally, SPM proved to reduce neutrophil infiltration and bacterial endotoxins in volunteers subjected to UV-killed E. coli skin inflammation (Motwani et al., 2018).

Collectively, these data indicate that SPMs act at multiple levels on cells involved in the pathophysiology of CF airway inflammation and proved effective in preclinical models and clinical trials to stimulate resolution of chronic infection and inflammation, thus opening the road for SPM-based human resolution pharmacology.

\section{CONCLUSION}

Anti-inflammatory drugs remain an area of intense research in CF, since it is unclear if and to what extent CFTR modulators will have a positive effect on the incipit and persistence of airway inflammation in patients. It is unlikely that these drugs will fully reverse the functional and structural damages present in patients with established disease or carry difficult to correct mutations. The development of drugs that stop excessive inflammation and promote resolution must proceed along with the identification of more suitable biochemical or cellular markers of effectiveness in patients. Furthermore, several aspects must be considered when evaluating new anti-inflammatories for CF: (1) mechanisms of actions and target cells/pathways, which should be broad and disease-related; (2) novelty of mode(s) of action with respect to traditional drugs used to limit inflammation (e.g., ibuprofen and steroids) that have provided little clinical benefits; (3) efficacy in appropriate preclinical models, including isolated cells, organs-on-a-chip derived, and biological samples (plasma, BAL) derived from patients, as well

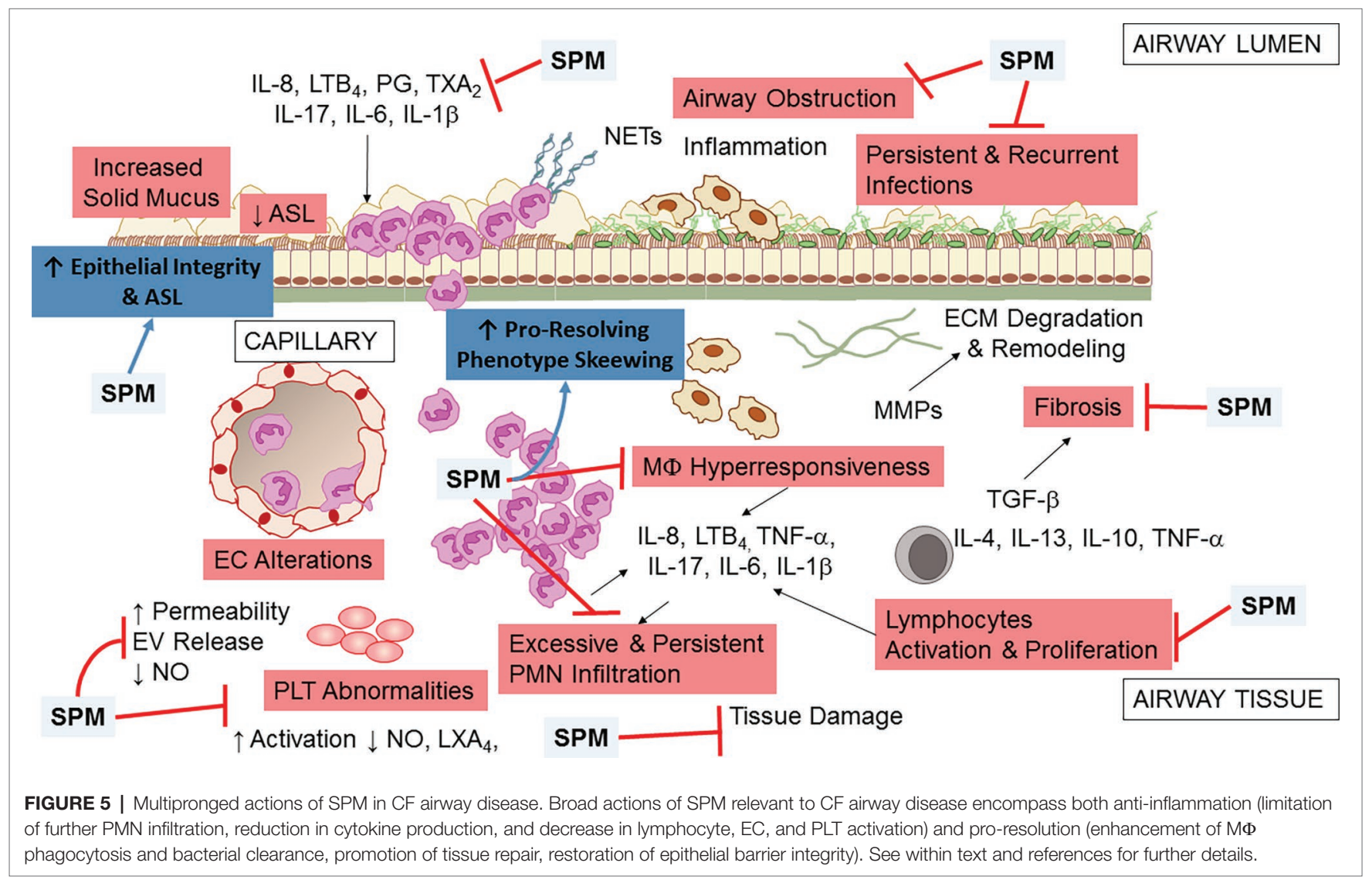


as animal systems; (4) toxicity; (5) in vivo impact on host defense mechanisms that are essential for containing infections; and (6) bioavailability and delivery methods that should take into account patients with lower compliance such as children.

Data from in vitro and in vivo studies indicate that SPMs are multi-pronged, potent regulators of inflammation and resolution, acting on multiple cell and molecular targets to limit the unwanted persistence of inflammation and tissue damage and accelerating the return to homeostasis (Figure 5). In addition, emerging results from clinical trials reporting safety and efficacy of SPM and molecules that stimulate their production encourage envisaging SPM as candidate drugs for treating chronic inflammation and infection in CF patients.

\section{REFERENCES}

Abdelmoaty, S., Wigerblad, G., Bas, D. B., Codeluppi, S., Fernandez-Zafra, T., El-Awady el, S., et al. (2013). Spinal actions of lipoxin A4 and 17(R)-resolvin D1 attenuate inflammation-induced mechanical hypersensitivity and spinal TNF release. PLoS One 8:e75543. doi: 10.1371/journal.pone.0075543

Abdulnour, R.-E. E., Dalli, J., Colby, J. K., Krishnamoorthy, N., Timmons, J. Y., Tan, S. H., et al. (2014). Maresin 1 biosynthesis during platelet-neutrophil interactions is organ-protective. Proc. Natl. Acad. Sci. USA 111, 16526-16531. doi: $10.1073 /$ pnas.1407123111

Al-Alawi, M., Buchanan, P., Verriere, V., Higgins, G., McCabe, O., Costello, R. W., et al. (2014). Physiological levels of lipoxin A4 inhibit ENaC and restore airway surface liquid height in cystic fibrosis bronchial epithelium. Phys. Rep. 2. doi: 10.14814/phy2.12093

Alexander, S. P. H., Kelly, E., Marrion, N. V., Peters, J. A., Faccenda, E., Harding, S. D., et al. (2017). The concise guide to pharmacology 2017/18: overview. Br. J. Pharmacol. 174, S1-S16. doi: 10.1111/bph.13882

Amison, R. T., O'Shaughnessy, B. G., Arnold, S., Cleary, S. J., Nandi, M., Pitchford, S. C., et al. (2018). Platelet depletion impairs host defense to pulmonary infection with Pseudomonas aeruginosa in mice. Am. J. Respir. Cell Mol. Biol. 58, 331-340. doi: 10.1165/rcmb.2017-0083OC

Arita, M., Bianchini, F., Aliberti, J., Sher, A., Chiang, N., Hong, S., et al. (2005). Stereochemical assignment, antiinflammatory properties, and receptor for the omega-3 lipid mediator resolvin E1. J. Exp. Med. 201, 713-722. doi: 10.1084/jem.20042031

Arita, M., Ohira, T., Sun, Y.-P., Elangovan, S., Chiang, N., and Serhan, C. N. (2007). Resolvin E1 selectively interacts with leukotriene B4 receptor BLT1 and ChemR23 to regulate inflammation. J. Immunol. 178, 3912-3917. doi: 10.4049/jimmunol.178.6.3912

Aursnes, M., Tungen, J. E., Vik, A., Colas, R., Cheng, C.-Y. C., Dalli, J., et al. (2014). Total synthesis of the lipid mediator PD1n-3 DPA: configurational assignments and anti-inflammatory and pro-resolving actions. J. Nat. Prod. 77, 910-916. doi: 10.1021/np4009865

Balough, K., McCubbin, M., Weinberger, M., Smits, W., Ahrens, R., and Fick, R. (1995). The relationship between infection and inflammation in the early stages of lung disease from cystic fibrosis. Pediatr. Pulmonol. 20, 63-70. doi: 10.1002/ ppul.1950200203

Bang, S., Xie, Y.-K., Zhang, Z.-J., Wang, Z., Xu, Z.-Z., and Ji, R.-R. (2018). GPR37 regulates macrophage phagocytosis and resolution of inflammatory pain. J. Clin. Invest. 128, 3568-3582. doi: 10.1172/JCI99888

Bannenberg, G. L., Chiang, N., Ariel, A., Arita, M., Tjonahen, E., Gotlinger, K. H., et al. (2005). Molecular circuits of resolution: formation and actions of resolvins and protectins. J. Immunol. 174, 4345-4355. doi: 10.4049/jimmunol.174.7.4345

Bannenberg, G., Moussignac, R. L., Gronert, K., Devchand, P. R., Schmidt, B. A., Guilford, W. J., et al. (2004). Lipoxins and novel 15-epi-lipoxin analogs display potent anti-inflammatory actions after oral administration. Br. J. Pharmacol. 143, 43-52. doi: 10.1038/sj.bjp.0705912

Barden, A. E., Mas, E., and Mori, T. A. (2016). n-3 Fatty acid supplementation and proresolving mediators of inflammation. Curr. Opin. Lipidol. 27, 26-32. doi: 10.1097/MOL.0000000000000262

\section{AUTHOR CONTRIBUTIONS}

AR wrote the first draft of the manuscript. All the authors have contributed to the final version of this review.

\section{FUNDING}

This work was supported by the U.S. Cystic Fibrosis Foundation (CFF) (RECCHI17I0 to AR) and the Italian Fondazione Ricerca Fibrosi Cistica (FFC) (FFC\#21/2014 and FFC\#19/2016). The authors obtained bursaries from FFC (DM and EI), CFF (EI), and Fondazione Umberto Veronesi (DM).

Barnig, C., Cernadas, M., Dutile, S., Liu, X., Perrella, M. A., Kazani, S., et al. (2013). Lipoxin A4 regulates natural killer cell and type 2 innate lymphoid cell activation in asthma. Sci. Transl. Med. 5, 174ra126. doi: 10.1126/ scitranslmed.3004812

Bedrossian, C. W., Greenberg, S. D., Singer, D. B., Hansen, J. J., and Rosenberg, H. S. (1976). The lung in cystic fibrosis. A quantitative study including prevalence of pathologic findings among different age groups. Hum. Pathol. 7, 195-204. doi: 10.1016/S0046-8177(76)80023-8

Bensalem, N., Ventura, A. P., Vallee, B., Lipecka, J., Tondelier, D., Davezac, N., et al. (2005). Down-regulation of the anti-inflammatory protein annexin A1 in cystic fibrosis knock-out mice and patients. Mol. Cell. Proteomics 4, 1591-1601. doi: 10.1074/mcp.M500019-MCP200

Birnbaum, Y., Ye, Y., Lin, Y., Freeberg, S. Y., Nishi, S. P., Martinez, J. D., et al. (2006). Augmentation of myocardial production of 15-epi-lipoxin-a4 by pioglitazone and atorvastatin in the rat. Circulation 114, 929-935. doi: 10.1161/ CIRCULATIONAHA.106.629907

Bonfield, T. L., Panuska, J. R., Konstan, M. W., Hilliard, K. A., Hilliard, J. B., Ghnaim, H., et al. (1995). Inflammatory cytokines in cystic fibrosis lungs. Am. J. Respir. Crit. Care Med. 152, 2111-2118. doi: 10.1164/ajrccm.152.6.8520783

Brennan, E. P., Nolan, K. A., Börgeson, E., Gough, O. S., McEvoy, C. M., Docherty, N. G., et al. (2013). Lipoxins attenuate renal fibrosis by inducing let-7c and suppressing TGFßR1. J. Am. Soc. Nephrol. 24, 627-637. doi: 10.1681/ASN.2012060550

Brezinski, D. A., Nesto, R. W., and Serhan, C. N. (1992). Angioplasty triggers intracoronary leukotrienes and lipoxin A4. Impact of aspirin therapy. Circulation 86, 56-63. doi: 10.1161/01.CIR.86.1.56

Brinkmann, V., Brinkmann, V., Reichard, U., Goosmann, C., Fauler, B., Uhlemann, Y., et al. (2004). Neutrophil extracellular traps kill bacteria Science 303, 1532-1535. doi: 10.1126/science.1092385

Bruscia, E. M., and Bonfield, T. L. (2016). CF lung immunity: the role of the macrophage. J. Innate Immun. 8, 550-563. doi: 10.1159/000446825

Bruscia, E. M., Zhang, P.-X., Ferreira, E., Caputo, C., Emerson, J. W., Tuck, D., et al. (2009). Macrophages directly contribute to the exaggerated inflammatory response in cystic fibrosis transmembrane conductance regulator ${ }^{-/-}$mice. Am. J. Respir. Cell Mol. Biol. 40, 295-304. doi: 10.1165/rcmb.2008-0170OC

Bruscia, E. M., Zhang, P.-X., Satoh, A., Caputo, C., Medzhitov, R., Shenoy, A., et al. (2011). Abnormal trafficking and degradation of TLR4 underlie the elevated inflammatory response in cystic fibrosis. J. Immunol. 186, 6990-6998. doi: 10.4049/jimmunol.1100396

Buchanan, P. J., Mcnally, P., Harvey, B. J., and Urbach, V. (2013). Lipoxin A4mediated KATP potassium channel activation results in cystic fibrosis airway epithelial repair. Am. J. Physiol. Lung Cell. Mol. Physiol. 305, L193-L201. doi: 10.1152/ajplung.00058.2013

Calder, P. C. (2011). Fatty acids and inflammation: the cutting edge between food and pharma. Eur. J. Pharmacol. 668(Suppl. 1), S50-S58. doi: 10.1016/j. ejphar.2011.05.085

Cantin, A. M., Hartl, D., Konstan, M. W., and Chmiel, J. F. (2015). Inflammation in cystic fibrosis lung disease: pathogenesis and therapy. J. Cyst. Fibros. 14, 419-430. doi: 10.1016/j.jcf.2015.03.003

Chiang, N., Bermudez, E. A., Ridker, P. M., Hurwitz, S., and Serhan, C. N. (2004). Aspirin triggers antiinflammatory 15-epi-lipoxin A4 and inhibits 
thromboxane in a randomized human trial. Proc. Natl. Acad. Sci. USA 101, 15178-15183. doi: 10.1073/pnas.0405445101

Chiang, N., Dalli, J., Colas, R. A., and Serhan, C. N. (2015). Identification of resolvin D2 receptor mediating resolution of infections and organ protection. J. Exp. Med. 212, 1203-1217. doi: 10.1084/jem.20150225

Chiang, N., de la Rosa, X., Libreros, S., and Serhan, C. N. (2017). Novel resolvin D2 receptor axis in infectious inflammation. J. Immunol. 198, 842-851. doi: 10.4049/jimmunol.1601650

Chiang, N., Fredman, G., Backhed, F., Oh, S. F., Vickery, T., Schmidt, B. A., et al. (2012). Infection regulates pro-resolving mediators that lower antibiotic requirements. Nature 484, 524-528. doi: 10.1038/nature11042

Chiang, N., Riley, I. R., Dalli, J., Rodriguez, A. R., Spur, B. W., and Serhan, C. N. (2018). New maresin conjugates in tissue regeneration pathway counters leukotriene D4-stimulated vascular responses. FASEB J. 32, 4043-4052. doi: 10.1096/f. 201701493R

Chiang, N., Serhan, C. N., Dahlen, S. E., Drazen, J. M., Hay, D. W., Rovati, G. E., et al. (2006). The lipoxin receptor ALX: potent ligand-specific and stereoselective actions in vivo. Pharmacol. Rev. 58, 463-487. doi: 10.1124/pr.58.3.4

Chiang, N., Takano, T., Arita, M., Watanabe, S., and Serhan, C. N. (2003). A novel rat lipoxin A4 receptor that is conserved in structure and function. Br. J. Pharmacol. 139, 89-98. doi: 10.1038/sj.bjp.0705220

Chmiel, J. F., Elborn, S., Constantine, S., and White, B. (2017). A double-blind, placebocontrolled phase 2 study in adults with cystic fibrosis of anabasum, A selective cannabinoid receptor Type 2 agonist. Pediatr. Pulmonol. S47, 317. doi: 10.1002/ppul.23840

Ciabattoni, G., Davi, G., Collura, M., Iapichino, L., Pardo, F., Ganci, A., et al. (2000). In vivo lipid peroxidation and platelet activation in cystic fibrosis. Am. J. Respir. Crit. Care Med. 162, 1195-1201. doi: 10.1164/ajrccm.162.4.9911071

Claria, J., and Serhan, C. N. (1995). Aspirin triggers previously undescribed bioactive eicosanoids by human endothelial cell-leukocyte interactions. Proc. Natl. Acad. Sci. USA 92, 9475-9479.

Codagnone, M., Cianci, E., Lamolinara, A., Mari, V. C., Nespoli, A., Isopi, E., et al. (2018). Resolvin D1 enhances the resolution of lung inflammation caused by long-term Pseudomonas aeruginosa infection. Mucosal Immunol. 11, 35-49. doi: 10.1038/mi.2017.36

Codagnone, M., Recchiuti, A., Lanuti, P., Pierdomenico, A. M., Cianci, E., Patruno, S., et al. (2017). Lipoxin A4 stimulates endothelial miR-126-5p expression and its transfer via microvesicles. FASEB J. doi: 10.1096/ff.201600952R

Colas, R. A., Dalli, J., Chiang, N., Vlasakov, I., Sanger, J. M., Riley, I. R., et al. (2016). Identification and actions of the maresin 1 metabolome in infectious inflammation. J. Immunol. 197, 4444-4452. doi: 10.4049/jimmunol.1600837

Colas, R. A., Shinohara, M., Dalli, J., Chiang, N., and Serhan, C. N. (2014). Identification and signature profiles for pro-resolving and inflammatory lipid mediators in human tissue. Am. J. Physiol. Cell Physiol. 307, C39-C54. doi: 10.1152/ajpcell.00024.2014

Croasdell, A., Sime, P. J., and Phipps, R. P. (2016). Resolvin D2 decreases TLR4 expression to mediate resolution in human monocytes. FASEB J. 30, 3181-3193. doi: 10.1096/fj.201600375R

Cystic Fibrosis Foundation (2016). 2016 Patient Registry Annual Data Report.

Dalli, J., Chiang, N., and Serhan, C. N. (2014). Identification of 14-series sulfido-conjugated mediators that promote resolution of infection and organ protection. Proc. Natl. Acad. Sci. USA 111, E4753-E4761. doi: 10.1073/ pnas. 1415006111

Dalli, J., Chiang, N., and Serhan, C. N. (2015a). Elucidation of novel 13-series resolvins that increase with atorvastatin and clear infections. Nat. Med. 21, 1071-1075. doi: 10.1038/nm.3911

Dalli, J., Colas, R. A., Arnardottir, H., and Serhan, C. N. (2017). Vagal regulation of group 3 innate lymphoid cells and the immunoresolvent PCTR1 controls infection resolution. Immunity 46, 92-105. doi: 10.1016/j.immuni.2016.12.009

Dalli, J., Colas, R. A., and Serhan, C. N. (2013a). Novel n-3 immunoresolvents: structures and actions. Sci. Rep. 3, 1940. doi: 10.1038/srep01940

Dalli, J., Consalvo, A. P., Ray, V., Di Filippo, C., D’amico, M., Mehta, N., et al. (2013b). Proresolving and tissue-protective actions of annexin A1-based cleavage-resistant peptides are mediated by formyl peptide receptor 2/lipoxin a4 receptor. J. Immunol. 190, 6478-6487. doi: 10.4049/jimmunol.1203000

Dalli, J., Ramon, S., Norris, P. C., Colas, R. A., and Serhan, C. N. (2015b). Novel proresolving and tissue-regenerative resolvin and protectin sulfido-conjugated pathways. FASEB J. 29, 2120-2136. doi: 10.1096/ f. $14-268441$
Dalli, J., Rosignoli, G., Hayhoe, R. P., Edelman, A., and Perretti, M. (2010). CFTR inhibition provokes an inflammatory response associated with an imbalance of the annexin A1 pathway. Am. J. Pathol. 177, 176-186. doi: 10.2353/ajpath.2010.091149

Dalli, J., Sanger, J. M., Rodriguez, A. R., Chiang, N., Spur, B. W., and Serhan, C. N. (2016a). Identification and actions of a novel third maresin conjugate in tissue regeneration: MCTR3. PLoS One 11:e0149319. doi: 10.1371/journal. pone.0149319

Dalli, J., and Serhan, C. N. (2012). Specific lipid mediator signatures of human phagocytes: microparticles stimulate macrophage efferocytosis and pro-resolving mediators. Blood 120, e60-e72. doi: 10.1182/blood-2012-04-423525

Dalli, J., Vlasakov, I., Riley, I. R., Rodriguez, A. R., Spur, B. W., Petasis, N. A., et al. (2016b). Maresin conjugates in tissue regeneration biosynthesis enzymes in human macrophages. Proc. Natl. Acad. Sci. USA 113, 12232-12237. doi: 10.1073/pnas. 1607003113

Dalli, J., Winkler, J. W., Colas, R. A., Arnardottir, H., Cheng, C. Y., Chiang, N., et al. (2013c). Resolvin D3 and aspirin-triggered resolvin D3 are potent immunoresolvents. Chem. Biol. 20, 188-201. doi: 10.1016/j.chembiol.2012.11.010

Davis, P. B., Drumm, M., and Konstan, M. W. (1996). Cystic fibrosis. Am. J. Respir. Crit. Care 154, 1229-1256. doi: 10.1164/ajrccm.154.5.8912731

de la Rosa, X., Norris, P. C., Chiang, N., Rodriguez, A. R., Spur, B. W., and Serhan, C. N. (2018). Identification and complete stereochemical assignments of the new resolvin conjugates in tissue regeneration in human tissues that stimulate proresolving phagocyte functions and tissue regeneration. Am. J. Pathol. 188, 950-966. doi: 10.1016/j.ajpath.2018.01.004

deCathelineau, A. M., and Henson, P. M. (2003). The final step in programmed cell death: phagocytes carry apoptotic cells to the grave. Essays Biochem. 39, 105-117. doi: 10.1042/bse0390105

Del Porto, P., Cifani, N., Guarnieri, S., Di Domenico, E. G., Mariggio, M. A., Spadaro, F., et al. (2011). Dysfunctional CFTR alters the bactericidal activity of human macrophages against Pseudomonas aeruginosa. PLoS One 6:e19970. doi: 10.1371/journal.pone.0019970

Deng, B., Wang, C.-W., Arnardottir, H. H., Li, Y., Cheng, C.-Y. C., Dalli, J., et al. (2014). Maresin biosynthesis and identification of maresin 2, a new anti-inflammatory and pro-resolving mediator from human macrophages. PLoS One 9:e102362. doi: 10.1371/journal.pone.0114886

Deriy, L. V., Gomez, E. A., Zhang, G., Beacham, D. W., Hopson, J. A., Gallan, A. J., et al. (2009). Disease-causing mutations in the cystic fibrosis transmembrane conductance regulator determine the functional responses of alveolar macrophages. J. Biol. Chem. 284, 35926-35938. doi: 10.1074/jbc. M109.057372

Devchand, P. R., Arita, M., Hong, S., Bannenberg, G., Moussignac, R. L., Gronert, K., et al. (2003). Human ALX receptor regulates neutrophil recruitment in transgenic mice: roles in inflammation and host defense. FASEB J. 17, 652-659. doi: 10.1096/f.02-0770com

Di, A., Brown, M. E., Deriy, L. V., Li, C., Szeto, F. L., Chen, Y., et al. (2006). CFTR regulates phagosome acidification in macrophages and alters bactericidal activity. Nat. Cell Biol. 8, 933-944. doi: 10.1038/ncb1456

Dona, M., Fredman, G., Schwab, J. M., Chiang, N., Arita, M., Goodarzi, A., et al. (2008). Resolvin E1, an EPA-derived mediator in whole blood, selectively counterregulates leukocytes and platelets. Blood 112, 848-855. doi: 10.1182/ blood-2007-11-122598

Donaldson, S. H., Pilewski, J. M., Griese, M., Cooke, J., Viswanathan, L., Tullis, E., et al. (2018). Tezacaftor/ivacaftor in subjects with cystic fibrosis and F508del/F508del-CFTR or F508del/G551D-CFTR. Am. J. Respir. Crit. Care Med. 197, 214-224. doi: 10.1164/rccm.201704-0717OC

Dufton, N., Hannon, R., Brancaleone, V., Dalli, J., Patel, H. B., Gray, M., et al. (2010). Anti-inflammatory role of the murine formyl-peptide receptor 2: ligand-specific effects on leukocyte responses and experimental inflammation. J. Immunol. 184, 2611-2619. doi: 10.4049/jimmunol.0903526

Edenius, C., Kumlin, M., Bjork, T., Anggard, A., and Lindgren, J. A. (1990). Lipoxin formation in human nasal polyps and bronchial tissue. FEBS Lett. 272, 25-28. doi: 10.1016/0014-5793(90)80440-T

Eickmeier, O., Fussbroich, D., Mueller, K., Serve, F., Smaczny, C., Zielen, S., et al. (2017). Pro-resolving lipid mediator Resolvin D1 serves as a marker of lung disease in cystic fibrosis. PLoS One 12:e0171249. doi: 10.1371/journal. pone. 0171249

Eickmeier, O., Seki, H., Haworth, O., Hilberath, J. N., Gao, F., Uddin, M., et al. (2013). Aspirin-triggered resolvin D1 reduces mucosal inflammation and 
promotes resolution in a murine model of acute lung injury. Mucosal Immunol. 6, 256-266. doi: 10.1038/mi.2012.66

Elborn, J. S., Ahuja, S., Springman, E., Mershon, J., Grosswald, R., and Rowe, S. M. (2018). EMPIRE-CF: a phase II randomized placebo-controlled trial of once-daily, oral acebilustat in adult patients with cystic fibrosis-study design and patient demographics. Contemp. Clin. Trials 72, 86-94. doi: 10.1016/j.cct.2018.07.014

Elborn, J. S., Horsley, A., MacGregor, G., Bilton, D., Grosswald, R., Ahuja, S., et al. (2017). Phase I studies of acebilustat: biomarker response and safety in patients with cystic fibrosis. Clin. Transl. Sci. 10, 28-34. doi: 10.1111/ cts. 12428

Elliott, R. B. (1976). A therapeutic trial of fatty acid supplementation in cystic fibrosis. Pediatrics 57, 474-479.

English, J. T., Norris, P. C., Hodges, R. R., Dartt, D. A., and Serhan, C. N. (2017). Identification and profiling of specialized pro-resolving mediators in human tears by lipid mediator metabolomics. Prostaglandins Leukot. Essent. Fatty Acids 117, 17-27. doi: 10.1016/j.plefa.2017.01.004

Fiore, S., Maddox, J. F., Perez, H. D., and Serhan, C. N. (1994). Identification of a human cDNA encoding a functional high affinity lipoxin A4 receptor. J. Exp. Med. 180, 253-260. doi: 10.1084/jem.180.1.253

Fiore, S., Ryeom, S. W., Weller, P. F., and Serhan, C. N. (1992). Lipoxin recognition sites. Specific binding of labeled lipoxin A4 with human neutrophils. J. Biol. Chem. 267, 16168-16176.

Fredman, G., Hellmann, J., Proto, J. D., Kuriakose, G., Colas, R. A., Dorweiler, B., et al. (2016). An imbalance between specialized pro-resolving lipid mediators and pro-inflammatory leukotrienes promotes instability of atherosclerotic plaques. Nat. Commun. 7, 1-11.

Fredman, G., Van Dyke, T. E., and Serhan, C. N. (2010). Resolvin E1 regulates adenosine diphosphate activation of human platelets. Arterioscler. Thromb. Vasc. Biol. 30, 2005-2013. doi: 10.1161/ATVBAHA.110.209908

Freedman, S. D., Blanco, P. G., Zaman, M. M., Shea, J. C., Ollero, M., Hopper, I. K., et al. (2004). Association of cystic fibrosis with abnormalities in fatty acid metabolism. N. Engl. J. Med. 350, 560-569. doi: 10.1056/ NEJMoa021218

Gangemi, S., Luciotti, G., D’Urbano, E., Mallamace, A., Santoro, D., Bellinghieri, G., et al. (2003). Physical exercise increases urinary excretion of lipoxin A4 and related compounds. J. Appl. Phys. 94, 2237-2240. doi: 10.1152/japplphysiol.01004.2002

Gangemi, S., Patella, V., Cianci, E., Saitta, S., Lattanzio, S., Florio, G., et al. (2012). Ultrarush venom immunotherapy and the lipoxin a4 inflammation resolution pathway. Ann. Allergy Asthma Immunol. 109, 226-227. doi: 10.1016/j. anai.2012.07.013

Gavins, F. N., Hughes, E. L., Buss, N. A., Holloway, P. M., Getting, S. J., and Buckingham, J. C. (2011). Leukocyte recruitment in the brain in sepsis: involvement of the annexin 1-FPR2/ALX anti-inflammatory system. FASEB J. 26, 4977-4989. doi: 10.1096/fj.12-205971

Gilljam, H., Strandvik, B., Ellin, Á., and Wiman, L.-G. (1986). Increased mole fraction of arachidonic acid in bronchial phospholipids in patients with cystic fibrosis. Scand. J. Clin. Lab. Invest. 46, 511-518.

Gilroy, D. W., Lawrence, T., Perretti, M., and Rossi, A. G. (2004). Inflammatory resolution: new opportunities for drug discovery. Nat. Rev. Drug Discovery 3, 401-416. doi: 10.1038/nrd1383

Gimbrone, M. a. (1995). Vascular endothelium: an integrator of pathophysiologic stimuli in atherosclerosis. Am. J. Cardiol. 75, 67B-70B. doi: 10.1016/0002-9149(95)80016-L

Gobbetti, T., Dalli, J., Colas, R. A., Federici Canova, D., Aursnes, M., Bonnet, D., et al. (2017). Protectin D1(n-3 DPA) and resolvin D5(n-3 DPA) are effectors of intestinal protection. Proc. Natl. Acad. Sci. USA 114, 3963-3968. doi: 10.1073/ pnas. 1617290114

Gordon, S. (2007). The macrophage: past, present and future. Eur. J. Immunol. 37, S9-S17. doi: 10.1002/eji.200737638

Gordon, S. (2016). Phagocytosis: an immunobiologic process. Immunity 44, 463-475. doi: 10.1016/j.immuni.2016.02.026

Gronert, K., Gewirtz, A., Madara, J. L., and Serhan, C. N. (1998). Identification of a human enterocyte lipoxin A4 receptor that is regulated by interleukin (IL)-13 and interferon gamma and inhibits tumor necrosis factor alphainduced IL-8 release. J. Exp. Med. 187, 1285-1294. doi: 10.1084/ jem.187.8.1285

Gronert, K., Martinsson-Niskanen, T., Ravasi, S., Chiang, N., and Serhan, C. N. (2001). Selectivity of recombinant human leukotriene $\mathrm{D}(4)$, leukotriene $\mathrm{B}(4)$, and lipoxin $\mathrm{A}(4)$ receptors with aspirin-triggered 15-epi-LXA(4) and regulation of vascular and inflammatory responses. Am. J. Pathol. 158, 3-9. doi: 10.1016/ S0002-9440(10)63937-5

Grumbach, Y., Quynh, N. V., Chiron, R., and Urbach, V. (2009). LXA4 stimulates ZO-1 expression and transepithelial electrical resistance in human airway epithelial (16HBE14o-) cells. Am. J. Physiol. Lung Cell. Mol. Physiol. 296, L101-L108. doi: 10.1152/ajplung.00018.2008

Guilford, W. J., Bauman, J. G., Skuballa, W., Bauer, S., Wei, G. P., Davey, D., et al. (2004). Novel 3-oxa lipoxin A4 analogues with enhanced chemical and metabolic stability have anti-inflammatory activity in vivo. J. Med. Chem. 47, 2157-2165. doi: 10.1021/jm0305691

Gutierrez, A. D., Sathyanarayana, P., Konduru, S., Ye, Y., Birnbaum, Y., and Bajaj, M. (2012). The effect of pioglitazone treatment on 15-epi-lipoxin A4 levels in patients with type 2 diabetes. Atherosclerosis 223, 204-208. doi: 10.1016/j.atherosclerosis.2012.04.016

Haas-Stapleton, E. J., Lu, Y., Hong, S., Arita, M., Favoreto, S., Nigam, S., et al. (2007). Candida albicans modulates host defense by biosynthesizing the proresolving mediator resolvin E1. PLoS One 2. doi: 10.1371/journal.pone.0001316

Haggie, P. M., and Verkman, A. S. (2007). Cystic fibrosis transmembrane conductance regulator-independent phagosomal acidification in macrophages. J. Biol. Chem. 282, 31422-31428. doi: 10.1074/jbc.M705296200

Hasturk, H., Kantarci, A., Ohira, T., Arita, M., Ebrahimi, N., Chiang, N., et al. (2006). RvE1 protects from local inflammation and osteoclast- mediated bone destruction in periodontitis. FASEB J. 20, 401-403. doi: 10.1096/fj.05-4724fje

Haworth, O., Cernadas, M., Yang, R., Serhan, C. N., and Levy, B. D. (2008). Resolvin E1 regulates interleukin 23, interferon-gamma and lipoxin A4 to promote the resolution of allergic airway inflammation. Nat. Immunol. 9, 873-879. doi: $10.1038 /$ ni. 1627

Headland, S. E., Jones, H. R., Norling, L. V., Kim, A., Souza, P. R., Corsiero, E., et al. (2015). Neutrophil-derived microvesicles enter cartilage and protect the joint in inflammatory arthritis. Sci. Transl. Med. 7, 315ra190. doi: 10.1126/ scitranslmed.aac5608

Hecht, I., Rong, J., Sampaio, A. L., Hermesh, C., Rutledge, C., Shemesh, R., et al. (2009). A novel peptide agonist of formyl-peptide receptor-like 1 (ALX) displays anti-inflammatory and cardioprotective effects. J. Pharmacol. Exp. Ther. 328, 426-434. doi: 10.1124/jpet.108.145821

Hellmann, J., Tang, Y., Kosuri, M., Bhatnagar, A., and Spite, M. (2011). Resolvin D1 decreases adipose tissue macrophage accumulation and improves insulin sensitivity in obese-diabetic mice. FASEB J. 25, 2399-2407. doi: 10.1096/fj.10-178657

Heltshe, S. L., Mayer-Hamblett, N., Burns, J. L., Khan, U., Baines, A., Ramsey, B. W., et al. (2015). Pseudomonas aeruginosa in cystic fibrosis patients with G551D-CFTR treated with ivacaftor. Clin. Infect. Dis. 60, 703-712. doi: $10.1093 / \mathrm{cid} / \mathrm{ciu} 944$

Higgins, G., Fustero Torre, C., Tyrrell, J., McNally, P., Harvey, B. J., and Urbach, V. (2016). Lipoxin A4 prevents tight junction disruption and delays the colonization of cystic fibrosis bronchial epithelial cells by Pseudomonas aeruginosa. Am. J. Physiol. Lung Cell. Mol. Physiol. 310, L1053-L1061. doi: 10.1152/ajplung.00368.2015

Hisert, K. B., Heltshe, S. L., Pope, C., Jorth, P., Wu, X., Edwards, R. M., et al. (2017). Restoring cystic fibrosis transmembrane conductance regulator function reduces airway bacteria and inflammation in people with cystic fibrosis and chronic lung infections. Am. J. Respir. Crit. Care Med. 195, 1617-1628. doi: 10.1164/rccm.201609-1954OC

Hong, S., Gronert, K., Devchand, P. R., Moussignac, R. L., and Serhan, C. N. (2003). Novel docosatrienes and 17S-resolvins generated from docosahexaenoic acid in murine brain, human blood, and glial cells. Autacoids in antiinflammation. J. Biol. Chem. 278, 14677-14687. doi: 10.1074/jbc.M300218200

Hybiske, K., Fu, Z., Schwarzer, C., Tseng, J., Do, J., Huang, N., et al. (2007). Effects of cystic fibrosis transmembrane conductance regulator and DeltaF508CFTR on inflammatory response, ER stress, and $\mathrm{Ca}^{2+}$ of airway epithelia. Am. J. Physiol. Lung Cell. Mol. Physiol. 293, L1250-L1260. doi: 10.1152/ajplung.00231.2007

Ishida, T., Yoshida, M., Arita, M., Nishitani, Y., Nishiumi, S., Masuda, A., et al. (2009). Resolvin E1, an endogenous lipid mediator derived from eicosapentaenoic acid, prevents dextran sulfate sodium-induced colitis. Inflamm. Bowel Dis. 16, 87-95. doi: 10.1002/ibd.21029

Isobe, Y., Arita, M., Iwamoto, R., Urabe, D., Todoroki, H., Masuda, K., et al. (2013). Stereochemical assignment and anti-inflammatory properties of the omega-3 lipid mediator resolvin E3. J. Biochem. 153, 355-360. doi: 10.1093/ $\mathrm{jb} / \mathrm{mvs} 151$ 
Isobe, Y., Arita, M., Matsueda, S., Iwamoto, R., Fujihara, T., Nakanishi, H., et al. (2012). Identification and structure determination of novel anti-inflammatory mediator resolvin E3, 17,18-dihydroxyeicosapentaenoic acid. J. Biol. Chem. 287, 10525-10534. doi: 10.1074/jbc.M112.340612

Jeanson, L., Guerrera, I. C., Papon, J.-F., Chhuon, C., Zadigue, P., PruliereEscabasse, V., et al. (2014). Proteomic analysis of nasal epithelial cells from cystic fibrosis patients. PLoS One 9:e108671. doi: 10.1371/journal.pone.0108671

Karp, C. L., Flick, L. M., Park, K. W., Softic, S., Greer, T. M., Keledjian, R., et al. (2004). Defective lipoxin-mediated anti-inflammatory activity in the cystic fibrosis airway. Nat. Immunol. 5, 388-392. doi: 10.1038/ni1056

Kasuga, K., Yang, R., Porter, T. F., Agrawal, N., Petasis, N. A., Irimia, D., et al. (2008). Rapid appearance of resolvin precursors in inflammatory exudates: novel mechanisms in resolution. J. Immunol. 181, 8677-8687. doi: 10.4049/ jimmunol.181.12.8677

Kong, X., Wu, S.-H., Zhang, L., and Chen, X.-Q. (2017). Pilot application of lipoxin A4 analog and lipoxin A4 receptor agonist in asthmatic children with acute episodes. Exp. Ther. Med. 14, 2284-2290. doi: 10.3892/etm.2017.4787

Konstan, M. W., Walenga, R. W., Hilliard, K. A., and Hilliard, J. B. (1993). Leukotriene B4 markedly elevated in the epithelial lining fluid of patients with cystic fibrosis. Am. Rev. Respir. Dis. 148, 896-901. doi: 10.1164/ajrccm/148.4_Pt_1.896

Kreda, S. M., Davis, C. W., and Rose, M. C. (2012). CFTR, mucins, and mucus obstruction in cystic fibrosis. Cold Spring Harb. Perspect. Med. 2:a009589. doi: 10.1101/cshperspect.a009589

Krishnamoorthy, S., Recchiuti, A., Chiang, N., Fredman, G., and Serhan, C. N. (2012). Resolvin D1 receptor stereoselectivity and regulation of inflammation and proresolving MicroRNAs. Am. J. Pathol. 180, 2018-2027. doi: 10.1016/j.ajpath.2012.01.028

Krishnamoorthy, S., Recchiuti, A., Chiang, N., Yacoubian, S., Lee, C. H., Yang, R., et al. (2010). Resolvin D1 binds human phagocytes with evidence for proresolving receptors. Proc. Natl. Acad. Sci. USA 107, 1660-1665. doi: 10.1073/pnas.0907342107

Kuo, P. T., Huang, N. N., and Bassett, D. R. (1962). The fatty acid composition of the serum chylomicrons and adipose tissue of children with cystic fibrosis of the pancreas. J. Pediatr. 60, 394-403. doi: 10.1016/S0022-3476(62)80065-1

Kushwah, R., Gagnon, S., and Sweezey, N. B. (2013). Intrinsic predisposition of naive cystic fibrosis $\mathrm{T}$ cells to differentiate towards a Th17 phenotype. Respir. Res. 14, 138. doi: 10.1186/1465-9921-14-138

Lands Larry, C., and Stanojevic, S. (2013). Oral non-steroidal anti-inflammatory drug therapy for lung disease in cystic fibrosis. Cochrane Database Syst. Rev. 4, 1-45. doi: 10.1002/14651858.CD001505.pub3

Lee, T. H., Crea, A. E., Gant, V., Spur, B. W., Marron, B. E., Nicolaou, K. C., et al. (1990). Identification of lipoxin A4 and its relationship to the sulfidopeptide leukotrienes C4, D4, and E4 in the bronchoalveolar lavage fluids obtained from patients with selected pulmonary diseases. Am. Rev. Respir. Dis. 141, 1453-1458. doi: 10.1164/ajrccm/141.6.1453

Lee, J. Y., Han, S. H., Park, M. H., Baek, B., Song, I.-S., Choi, M.-K., et al. (2018). Neuronal SphK1 acetylates COX2 and contributes to pathogenesis in a model of Alzheimer's disease. Nat. Commun. 9, 1479. doi: 10.1038/ s41467-018-03674-2

Lee, H. N., and Surh, Y. J. (2013). Resolvin D1-mediated NOX2 inactivation rescues macrophages undertaking efferocytosis from oxidative stress-induced apoptosis. Biochem. Pharmacol. doi: 10.1016/j.bcp.2013.07.002

Leoni, G., Neumann, P. A., Kamaly, N., Quiros, M., Nishio, H., Jones, H. R., et al. (2015). Annexin A1-containing extracellular vesicles and polymeric nanoparticles promote epithelial wound repair. J. Clin. Invest. 125, 1215-1227. doi: 10.1172/JCI76693

Levy, B. D., Kohli, P., Gotlinger, K., Haworth, O., Hong, S., Kazani, S., et al. (2007). Protectin D1 is generated in asthma, and dampens airway inflammation, and hyperresponsiveness. J. Immunol. 178, 496-502.

Levy, B. D., Romano, M., Chapman, H. A., Reilly, J. J., Drazen, J., and Serhan, C. N. (1993). Human alveolar macrophages have 15-lipoxygenase and generate 15(S)-hydroxy-5,8,11-cis-13-trans-eicosatetraenoic acid and lipoxins. J. Clin. Invest. 92, 1572-1579. doi: 10.1172/JCI116738

Lindberg, U., Svensson, L., Hellmark, T., Segelmark, M., and Shannon, O. (2018). Increased platelet activation occurs in cystic fibrosis patients and correlates to clinical status. Thromb. Res. 162, 32-37. doi: 10.1016/j. thromres.2017.12.012

Livraghi-Butrico, A., Grubb, B. R., Wilkinson, K. J., Volmer, A. S., Burns, K. A., Evans, C. M., et al. (2017). Contribution of mucus concentration and secreted mucins Muc5ac and Muc5b to the pathogenesis of muco-obstructive lung disease. Mucosal Immunol. 10, 395-407. doi: 10.1038/mi.2016.63

Majno, G. (1991). The healing hand: Man and wound in the ancient world. Cambridge, MA: Harvard University Press.

Mall, M. A. (2016). Unplugging mucus in cystic fibrosis and chronic obstructive pulmonary disease. Ann. Am. Thorac. Soc. 13, S177-S185.

Marcheselli, V. L., Hong, S., Lukiw, W. J., Tian, X. H., Gronert, K., Musto, A., et al. (2003). Novel docosanoids inhibit brain ischemia-reperfusion-mediated leukocyte infiltration and pro-inflammatory gene expression. J. Biol. Chem. 278, 43807-43817. doi: 10.1074/jbc.M305841200

Marcheselli, V. L., Mukherjee, P. K., Arita, M., Hong, S., Antony, R., Sheets, K., et al. (2010). Neuroprotectin D1/protectin D1 stereoselective and specific binding with human retinal pigment epithelial cells and neutrophils. Prostaglandins Leukot. Essent. Fatty Acids 82, 27-34. doi: 10.1016/j.plefa.2009.10.010

Markworth, J. F., Vella, L., Lingard, B. S., Tull, D. L., Rupasinghe, T. W., Sinclair, A. J., et al. (2013). Human inflammatory and resolving lipid mediator responses to resistance exercise and ibuprofen treatment. Am. J. Physiol. Regul. Integr. Comp. Physiol. 305, R1281-R1296. doi: 10.1152/ ajpregu.00128.2013

Mas, E., Croft, K. D., Zahra, P., Barden, A., and Mori, T. A. (2012). Resolvins D1, D2, and other mediators of self-limited resolution of inflammation in human blood following n-3 fatty acid supplementation. Clin. Chem. 58, 1476-1484. doi: 10.1152/ajpregu.00128.2013

Matte, A., Recchiuti, A., Federti, E., Koehl, B., El Nemer, W., Tharaux, P., et al. (2019). Resolution of sickle cell disease associated inflammation and tissue damage with 17R-resolvin D1. Blood. doi: 10.1182/blood-2018-07-865378

Mattoscio, D., Evangelista, V., De Cristofaro, R., Recchiuti, A., Pandolfi, A., Di Silvestre, S., et al. (2010). Cystic fibrosis transmembrane conductance regulator (CFTR) expression in human platelets: impact on mediators and mechanisms of the inflammatory response. FASEB J. 24, 3970-3980. doi: 10.1096/fj.10-159921

McShane, D., Davies, J. C., Davies, M. G., Bush, A., Geddes, D. M., and Alton, E. W. F. W. (2003). Airway surface pH in subjects with cystic fibrosis. Eur. Respir. J. 21, 37-42. doi: 10.1183/09031936.03.00027603

Merched, A. J., Ko, K., Gotlinger, K. H., Serhan, C. N., and Chan, L. (2008). Atherosclerosis: evidence for impairment of resolution of vascular inflammation governed by specific lipid mediators. FASEB J. 22, 3595-3606. doi: 10.1096/ fj.08-112201

Montero-Melendez, T., Madeira, M. F. M., Norling, L. V., Alsam, A., Curtis, M. A., da Silva, T. A., et al. (2014). Association between periodontal disease and inflammatory arthritis reveals modulatory functions by melanocortin receptor type 3. Am. J. Pathol. 184, 2333-2341. doi: 10.1016/j. ajpath.2014.04.009

Morris, T., Stables, M., Colville-Nash, P., Newson, J., Bellingan, G., De Souza, P. M., et al. (2010). Dichotomy in duration and severity of acute inflammatory responses in humans arising from differentially expressed proresolution pathways. Proc. Natl. Acad. Sci. USA 107, 8842-8847. doi: 10.1073/ pnas. 1000373107

Morris, T., Stables, M., Hobbs, A., De Souza, P., Colville-Nash, P., Warner, T., et al. (2009). Effects of low-dose aspirin on acute inflammatory responses in humans. J. Immunol. 183, 2089-2096. doi: 10.4049/jimmunol.0900477

Motwani, M. P., Bennett, F., Norris, P. C., Maini, A. A., George, M. J., Newson, J., et al. (2017). Potent anti-inflammatory and pro-resolving effects of anabasum in a human model of self-resolving acute inflammation. Clin. Pharmacol. Ther

Motwani, M. P., Colas, R. A., George, M. J., Flint, J. D., Dalli, J., RichardLoendt, A., et al. (2018). Pro-resolving mediators promote resolution in a human skin model of UV-killed Escherichia coli-driven acute inflammation. JCI Insight 3. doi: 10.1172/jci.insight.94463

Muhlebach, M. S., and Noah, T. L. (2002). Endotoxin activity and inflammatory markers in the airways of young patients with cystic fibrosis. Am. J. Respir. Crit. Care 165, 911-915. doi: 10.1164/ajrccm.165.7.2107114

Muhlebach, M. S., Stewart, P. W., Leigh, M. W., and Noah, T. L. (1999). Quantitation of inflammatory responses to bacteria in young cystic fibrosis and control patients. Am. J. Respir. Crit. Care 160, 186-191. doi: 10.1164/ ajrccm.160.1.9808096

Nathan, C., and Ding, A. (2010). Nonresolving inflammation. Cell 140, 871-882. doi: $10.1016 /$ j.cell.2010.02.029

Navarro-Xavier, R. A., Newson, J., Silveira, V. L., Farrow, S. N., Gilroy, D. W., and Bystrom, J. (2010). A new strategy for the identification of novel 
molecules with targeted proresolution of inflammation properties. J. Immunol. 184, 1516-1525. doi: 10.4049/jimmunol.0902866

Nichols, D. P., and Chmiel, J. F. (2015). Inflammation and its genesis in cystic fibrosis. Pediatr. Pulmonol. 50 (Suppl. 4), S39-S56. doi: 10.1002/ppul.23242

Nick, J. A., and Nichols, D. P. (2016). Diagnosis of adult patients with cystic fibrosis. Clin. Chest Med. 37, 47-57. doi: 10.1016/j.ccm.2015.11.006

Nielsen, M. M. B., Lambertsen, K. L., Clausen, B. H., Meyer, M., Bhandari, D. R., Larsen, S. T., et al. (2016). Mass spectrometry imaging of biomarker lipids for phagocytosis and signalling during focal cerebral ischaemia. Sci. Rep. 6:39571. doi: 10.1038/srep39571

Nigam, S., Fiore, S., Luscinskas, F. W., and Serhan, C. N. (1990). Lipoxin A4 and lipoxin B4 stimulate the release but not the oxygenation of arachidonic acid in human neutrophils: dissociation between lipid remodeling and adhesion. J. Cell. Physiol. 143, 512-523. doi: 10.1002/jcp.1041430316

Noah, T. L., Black, H. R., Cheng, P. W., Wood, R. E., and Leigh, M. W. (1997). Nasal and bronchoalveolar lavage fluid cytokines in early cystic fibrosis. J. Infect. Dis. 175, 638-647. doi: 10.1093/infdis/175.3.638

Norling, L. V., Spite, M., Yang, R., Flower, R. J., Perretti, M., and Serhan, C. N. (2011). Cutting edge: Humanized nano-proresolving medicines mimic inflammation-resolution and enhance wound healing. J. Immunol. 186, 5543-5547. doi: 10.4049/jimmunol.1003865

Norling, L. V., Dalli, J., Flower, R. J., Serhan, C. N., and Perretti, M. (2012). Resolvin D1 limits polymorphonuclear leukocyte recruitment to inflammatory loci: receptor-dependent actions. Arterioscler. Thromb. Vasc. Biol. 32, 1970-1978. doi: 10.1161/ATVBAHA.112.249508

Norling, L. V., Headland, S. E., Dalli, J., Arnardottir, H. H., Haworth, O., Jones, H. R., et al. (2016). Proresolving and cartilage-protective actions of resolvin D1 in inflammatory arthritis. JCI Insight 1:e85922. doi: 10.1172/jci.insight.85922

O'Sullivan, B. P., Linden, M. D., Frelinger, A. L. 3rd., Barnard, M. R., SpencerManzon, M., Morris, J. E., et al. (2005). Platelet activation in cystic fibrosis. Blood 105, 4635-4641. doi: 10.1182/blood-2004-06-2098

Ogawa, N., and Kobayashi, Y. (2009). Total synthesis of resolvin E1. Tetrahedron Lett. 50, 6079-6082. doi: 10.1016/j.tetlet.2009.08.061

Oh, S. F., Dona, M., Fredman, G., Krishnamoorthy, S., Irimia, D., and Serhan, C. N. (2012). Resolvin e2 formation and impact in inflammation resolution. J. Immunol. 188, 4527-4534. doi: 10.4049/jimmunol.1103652

Oh, S. F., Pillai, P. S., Recchiuti, A., Yang, R., and Serhan, C. N. (2011). Pro-resolving actions and stereoselective biosynthesis of $18 \mathrm{~S}$ E-series resolvins in human leukocytes and murine inflammation. J. Clin. Invest. 121, 569-581. doi: 10.1172/JCI42545

Oh, S. F., Vickery, T. W., and Serhan, S. N. (2011). Chiral lipidomics of E-series resolvins: aspirin and the biosynthesis of novel mediators. Biochim. Biophys. Acta 1811, 737-747.

Ohira, T., Arita, M., Omori, K., Recchiuti, A., Van Dykeand, T. E., and Serhan, C. N. (2010). Resolvin E1 receptor activation signals phosphorylation and phagocytosis. J. Biol. Chem. 285, 3451-3461. doi: 10.1074/jbc.M109.044131

Pamplona, F. A., Ferreira, J., Menezes de Lima, O. J., Duarte, F. S., Bento, A. F., Forner, S., et al. (2012). Anti-inflammatory lipoxin A4 is an endogenous allosteric enhancer of CB1 cannabinoid receptor. Proc. Natl. Acad. Sci. USA 109, 21134-21139. doi: 10.1073/pnas.1202906109

Papayianni, A., Serhan, C. N., and Brady, H. R. (1996). Lipoxin A4 and B4 inhibit leukotriene-stimulated interactions of human neutrophils and endothelial cells. J. Immunol. 156, 2264-2272.

Paul-Clark, M. J., Van Cao, T., Moradi-Bidhendi, N., Cooper, D., and Gilroy, D. W. (2004). 15-epi-lipoxin A4-mediated induction of nitric oxide explains how aspirin inhibits acute inflammation. J. Exp. Med. 200, 69-78. doi: 10.1084/jem.20040566

Perez, A., Issler, A. C., Cotton, C. U., Kelley, T. J., Verkman, A. S., and Davis, P. B. (2006). CFTR inhibition mimics the cystic fibrosis inflammatory profile. AJP Lung Cell. Mol. Physiol. 292, L383-L395.

Perretti, M., Chiang, N., La, M., Fierro, I. M., Marullo, S., Getting, S. J., et al. (2002). Endogenous lipid- and peptide-derived anti-inflammatory pathways generated with glucocorticoid and aspirin treatment activate the lipoxin A4 receptor. Nat. Med. 8, 1296-1302. doi: 10.1038/nm786

Perretti, M., and Flower, R. J. (2004). Annexin 1 and the biology of the neutrophil. J. Leukocyte Biol. 76, 25-29. doi: 10.1189/jlb.1103552

Perretti, M., Leroy, X., Bland, E. J., and Montero-Melendez, T. (2015). Resolution Pharmacology: Opportunities for Therapeutic Innovation in Inflammation. Trends Pharmacol. Sci. 36, 737-755. doi: 10.1016/j.tips.2015.07.007
Pierdomenico, A. M., Patruno, S., Codagnone, M., Simiele, F., Mari, V. C., Plebani, R., et al. (2017). MicroRNA-181b is increased in cystic fibrosis cells and impairs lipoxin A4 receptor-dependent mechanisms of inflammation resolution and antimicrobial defense. Sci. Rep. 7, 1-10. doi: 10.1038/ s41598-017-14055-y

Pierdomenico, A. M., Recchiuti, A., Simiele, F., Codagnone, M., Mari, V. C., Davì, G., et al. (2015). MicroRNA-181b regulates ALX/FPR2 receptor expression and proresolution signaling in human macrophages. J. Biol. Chem. 290, 3592-3600. doi: 10.1074/jbc.M114.592352

Pillai, P. S., Leeson, S., Porter, T. F., Owens, C. D., Kim, J. M., Conte, M. S., et al. (2012). Chemical mediators of inflammation and resolution in postoperative abdominal aortic aneurysm patients. Inflammation 35, 98-113. doi: 10.1007/s10753-011-9294-8

Pistorius, K., Souza, P. R., De Matteis, R., Austin-Williams, S., Primdahl, K. G., Vik, A., et al. (2018). PDn-3 DPA pathway regulates human monocyte differentiation and macrophage function. Cell Chem. Biol. 25, 749.e9-760.e9. doi: 10.1016/j.chembiol.2018.04.017

Planagumà, A., Kazani, S., Marigowda, G., Haworth, O., Mariani, T. J., Israel, E., et al. (2008). Airway lipoxin A4 generation and lipoxin A4 receptor expression are decreased in severe asthma. Am. J. Respir. Crit. Care Med. 178, 574-582. doi: 10.1164/rccm.200801-061OC

Poore, S., Berry, B., Eidson, D., McKie, K. T., and Harris, R. A. (2013). Evidence of vascular endothelial dysfunction in young patients with cystic fibrosis. Chest 143, 939-945. doi: 10.1378/chest.12-1934

Psychogios, N., Hau, D. D., Peng, J., Guo, A. C., Mandal, R., Bouatra, S., et al. (2011). The human serum metabolome. PLoS One 6:e16957. doi: 10.1371/ journal.pone.0016957

Ramon, S., Dalli, J., Sanger, J. M., Winkler, J. W., Aursnes, M., Tungen, J. E., et al. (2016). The protectin PCTR1 is produced by human M2 macrophages and enhances resolution of infectious inflammation. Am. J. Pathol. 186, 962-973. doi: 10.1016/j.ajpath.2015.12.012

Recchiuti, A., Cianci, E., Simiele, F., and Romano, M. (2016). "Lipoxins, resolvins, and the resolution of inflammation" in Lipoxygenases in inflammation. (New York, USA: Springer), 211-239.

Recchiuti, A., Codagnone, M., Pierdomenico, A. M., Rossi, C., Mari, V. C., Cianci, E., et al. (2014). Immunoresolving actions of oral resolvin D1 include selective regulation of the transcription machinery in resolution-phase mouse macrophages. FASEB J. 28, 3090-3102. doi: 10.1096/fj.13-248393

Recchiuti, A., Krishnamoorthy, S., Fredman, G., Chiang, N., and Serhan, C. N. (2011). MicroRNAs in resolution of acute inflammation: identification of novel resolvin D1-miRNA circuits. FASEB J. 25, 544-560. doi: 10.1096/ f. 10-169599

Ringholz, F. C., Buchanan, P. J., Clarke, D. T., Millar, R. G., McDermott, M., Linnane, B., et al. (2014). Reduced 15-lipoxygenase 2 and lipoxin A4/ leukotriene B4 ratio in children with cystic fibrosis. Eur. Respir. J. 44, 394-404. doi: 10.1183/09031936.00106013

Ringholz, F. C., Higgins, G., Hatton, A., Sassi, A., Moukachar, A., Fustero-Torre, C., et al. (2018). Resolvin D1 regulates epithelial ion transport and inflammation in cystic fibrosis airways. J. Cyst. Fibros. 17, 607-615. doi: 10.1016/j.jcf.2017.11.017

Rodriguez, A., and Spur, B. (2015a). First total synthesis of pro-resolving and tissue-regenerative Maresin sulfido-conjugates. Tetrahedron Letters 56.25. 3936-3940. doi: 10.1016/j.tetlet.2015.04.131

Rodriguez, A., and Spur, B. (2015b). Total synthesis of pro-resolving and tissueregenerative Protectin sulfido-conjugates. Tetrahedron letters 56.42. 5811-5815. doi: 10.1016/j.tetlet.2015.09.020

Rodriguez, A. R., and Spur, B. W. (2017). First total synthesis of pro-resolving and tissue-regenerative resolvin sulfido-conjugates. Tetrahedron Lett. 58, 1662-1668. doi: 10.1016/j.tetlet.2017.03.041

Roesch, E. A., Nichols, D. P., and Chmiel, J. F. (2018). Inflammation in cystic fibrosis: an update. Pediatr. Pulmonol. 53, S30-S50. doi: 10.1002/ppul.24129

Romano, M., Chen, X. S., Takahashi, Y., Yamamoto, S., Funk, C. D., and Serhan, C. N. (1993). Lipoxin synthase activity of human platelet 12-lipoxygenase. Biochem. J. 296 (Pt 1), 127-133. doi: 10.1042/bj2960127

Romano, M., Cianci, E., Simiele, F., and Recchiuti, A. (2015). Lipoxins and aspirin-triggered lipoxins in resolution of inflammation. Eur. J. Pharmacol. 760, 49-63. doi: 10.1016/j.ejphar.2015.03.083

Romano, M., Collura, M., Lapichino, L., Pardo, F., Falco, A., Chiesa, P. L., et al. (2001). Endothelial perturbation in cystic fibrosis. Thromb. Haemost. 86, 1363-1367. doi: 10.1055/s-0037-1616736 
Romano, M., and Serhan, C. N. (1992). Lipoxin generation by permeabilized human platelets. Biochemistry 31, 8269-8277. doi: 10.1021/bi00150a021

Rondina, M. T., Weyrich, A. S., and Zimmerman, G. A. (2013). Platelets as cellular effectors of inflammation in vascular diseases. Circ. Res. 112, 1506-1519. doi: 10.1161/CIRCRESAHA.113.300512

Rowe, S. M., Heltshe, S. L., Gonska, T., Donaldson, S. H., Borowitz, D., Gelfond, D., et al. (2014). Clinical mechanism of the cystic fibrosis transmembrane conductance regulator potentiator ivacaftor in G551Dmediated cystic fibrosis. Am. J. Respir. Crit. Care Med. 190, 175-184. doi: 10.1164/rccm.201404-0703OC

Samuelsson, B., Dahlen, S. E., Lindgren, J. A., Rouzer, C. A., and Serhan, C. N. (1987). Leukotrienes and lipoxins: structures, biosynthesis, and biological effects. Science 237, 1171-1176. doi: 10.1126/science.2820055

Sasaki, A., Fukuda, H., Shiida, N., Tanaka, N., Furugen, A., Ogura, J., et al. (2015). Determination of omega-6 and omega-3 PUFA metabolites in human urine samples using UPLC/MS/MS. Anal. Bioanal. Chem. 407, 1625-1639. doi: $10.1007 /$ s00216-014-8412-5

Savill, J. S., Henson, P. M., and Haslett, C. (1989a). Phagocytosis of aged human neutrophils by macrophages is mediated by a novel "charge-sensitive" recognition mechanism. J. Clin. Invest. 84, 1518-1527.

Savill, J. S., Wyllie, A. H., Henson, J. E., Walport, M. J., Henson, P. M., and Haslett, C. (1989b). Macrophage phagocytosis of aging neutrophils in inflammation. Programmed cell death in the neutrophil leads to its recognition by macrophages. J. Clin. Invest. 83, 865-875.

Schwab, J. M., Chiang, N., Arita, M., and Serhan, C. N. (2007). Resolvin E1 and protectin D1 activate inflammation-resolution programmes. Nature 447, 869-874. doi: 10.1038/nature05877

Serhan, C. N., Brain, S. D., Buckley, C. D., Gilroy, D. W., Haslett, C., O’Neill, L. A., et al. (2007). Resolution of inflammation: state of the art, definitions and terms. FASEB J. 21, 325-332. doi: 10.1096/fj.06-7227rev

Serhan, C. N., Clish, C. B., Brannon, J., Colgan, S. P., Chiang, N., and Gronert, K. (2000). Novel functional sets of lipid-derived mediators with antiinflammatory actions generated from omega-3 fatty acids via cyclooxygenase 2-nonsteroidal antiinflammatory drugs and transcellular processing. J. Exp. Med. 192, 1197-1204. doi: 10.1084/jem.192.8.1197

Serhan, C. N., Dalli, J., Karamnov, S., Choi, A., Park, C. K., Xu, Z. Z., et al. (2012). Macrophage proresolving mediator maresin 1 stimulates tissue regeneration and controls pain. FASEB J. 26, 1755-1765. doi: 10.1096/ f. $11-201442$

Serhan, C. N., Gotlinger, K., Hong, S., Lu, Y., Siegelman, J., Baer, T., et al. (2006). Anti-inflammatory actions of neuroprotectin D1/protectin D1 and its natural stereoisomers: assignments of dihydroxy-containing docosatrienes. J. Immunol. 176, 1848-1859. doi: 10.4049/jimmunol.176.3.1848

Serhan, C. N., Hamberg, M., and Samuelsson, B. (1984). Trihydroxytetraenes: a novel series of compounds formed from arachidonic acid in human leukocytes. Biochem. Biophys. Res. Commun. 118, 943-949. doi: 10.1016/0006-291X(84)91486-4

Serhan, C. N., Hong, S., Gronert, K., Colgan, S. P., Devchand, P. R., Mirick, G., et al. (2002). Resolvins: a family of bioactive products of omega-3 fatty acid transformation circuits initiated by aspirin treatment that counter proinflammation signals. J. Exp. Med. 196, 1025-1037. doi: 10.1084/jem.20020760

Serhan, C. N., and Levy, B. D. (2018). Resolvins in inflammation: emergence of the pro-resolving superfamily of mediators. J. Clin. Invest. 128, 2657-2669. doi: $10.1172 /$ JCI97943

Serhan, C. N., and Sheppard, K. A. (1990). Lipoxin formation during human neutrophilplatelet interactions. Evidence for the transformation of leukotriene A4 by platelet 12-lipoxygenase in vitro. J. Clin. Invest. 85, 772-780. doi: 10.1172/JCI114503

Serhan, C. N., Yang, R., Martinod, K., Kasuga, K., Pillai, P. S., Porter, T. F., et al. (2009). Maresins: novel macrophage mediators with potent antiinflammatory and proresolving actions. J. Exp. Med. 206, 15-23. doi: $10.1084 /$ jem. 20081880

Simiele, F., Recchiuti, A., Mattoscio, D., De Luca, A., Cianci, E., Franchi, S., et al. (2012). Transcriptional regulation of the human FPR2/ALX gene: evidence of a heritable genetic variant that impairs promoter activity. FASEB J. 26, 1323-1333. doi: $10.1096 /$ ff.11-198069

Simiele, F., Recchiuti, A., Patruno, S., Plebani, R., Pierdomenico, A. M., Codagnone, M., et al. (2016). Epigenetic regulation of the formyl peptide receptor 2 gene. Biochim. Biophys. Acta Gene Regul. Mech. 1859, 1252-1258. doi: 10.1016/j.bbagrm.2016.07.007
Spite, M., Norling, L. V., Summers, L., Yang, R., Cooper, D., Petasis, N. A., et al. (2009). Resolvin D2 is a potent regulator of leukocytes and controls microbial sepsis. Nature 461, 1287-1291. doi: 10.1038/nature08541

Stables, M. J., Shah, S., Camon, E. B., Lovering, R. C., Newson, J., Bystrom, J., et al. (2011). Transcriptomic analyses of murine resolution-phase macrophages. Blood 118, e192-e208. doi: 10.1182/blood-2011-04-345330

Stoltz, D. A., Meyerholz, D. K., and Welsh, M. J. (2015). Origins of cystic fibrosis lung disease. N. Engl. J. Med. 372, 351-362. doi: 10.1056/NEJMra1300109

Sun, Y.-P., Oh, S. F., Uddin, J., Yang, R., Gotlinger, K., Campbell, E., et al. (2007). Resolvin D1 and its aspirin-triggered 17R epimer. Stereochemical assignments, anti-inflammatory properties, and enzymatic inactivation. J. Biol. Chem. 282, 9323-9334. doi: 10.1074/jbc.M609212200

Sun, Y. P., Tjonahen, E., Keledjian, R., Zhu, M., Yang, R., Recchiuti, A., et al. (2009). Anti-inflammatory and pro-resolving properties of benzo-lipoxin A(4) analogs. Prostaglandins Leukot. Essent. Fatty Acids 81, 357-366. doi: 10.1016/j.plefa.2009.09.004

Svensson, C. I., Zattoni, M., and Serhan, C. N. (2007). Lipoxins and aspirintriggered lipoxin inhibit inflammatory pain processing. J. Exp. Med. 204, 245-252. doi: 10.1084/jem.20061826

Tabeling, C., Yu, H., Wang, L., Ranke, H., Goldenberg, N. M., Zabini, D., et al. (2015). CFTR and sphingolipids mediate hypoxic pulmonary vasoconstriction. Proc. Natl. Acad. Sci. USA 112, E1614-E1623. doi: 10.1073/ pnas. 1421190112

Takano, T., Fiore, S., Maddox, J. F., Brady, H. R., Petasis, N. A., and Serhan, C. N. (1997). Aspirin-triggered 15-epi-lipoxin A4 (LXA4) and LXA4 stable analogues are potent inhibitors of acute inflammation: evidence for antiinflammatory receptors. J. Exp. Med. 185, 1693-1704. doi: 10.1084/ jem.185.9.1693

Tang, Y., Zhang, M. J., Hellmann, J., Kosuri, M., Bhatnagar, A., and Spite, M. (2012). Proresolution therapy for the treatment of delayed healing of diabetic wounds. Diabetes 62, 618-627. doi: 10.2337/db12-0684

Tirouvanziam, R., de Bentzmann, S., Hubeau, C., Hinnrasky, J., Jacquot, J., Peault, B., et al. (2000). Inflammation and infection in naive human cystic fibrosis airway grafts. Am. J. Respir. Cell Mol. Biol. 23, 121-127. doi: 10.1165/ ajrcmb.23.2.4214

Titos, E., Rius, B., López-Vicario, C., Alcaraz-Quiles, J., García-Alonso, V., Lopategi, A., et al. (2016). Signaling and immunoresolving actions of resolvin D1 in inflamed human visceral adipose tissue. J. Immunol. 197, 3360-3370.

Tjonahen, E., Oh, S. F., Siegelman, J., Elangovan, S., Percarpio, K. B., Hong, S. et al. (2006). Resolvin E2: identification and anti-inflammatory actions: pivotal role of human 5-lipoxygenase in resolvin E series biosynthesis. Chem. Biol. 13, 1193-1202. doi: 10.1016/j.chembiol.2006.09.011

Totani, L., Plebani, R., Piccoli, A., Di Silvestre, S., Lanuti, P., Recchiuti, A., et al. (2017). Mechanisms of endothelial cell dysfunction in cystic fibrosis. Biochim. Biophys. Acta Mol. Basis Dis. 1863, 3243-3253. doi: 10.1016/j. bbadis.2017.08.011

Tousson, A., Van Tine, B. A., Naren, A. P., Shaw, G. M., and Schwiebert, L. M. (1998). Characterization of CFTR expression and chloride channel activity in human endothelia. Am. J. Physiol. 275, C1555-C1564.

Underwood, B. A., Denning, C. R., and Navab, M. (1972). Polyunsaturated fatty acids and tocopherol levels in patients with cystic fibrosis. Annals of the New York Academy of Sciences. 203, 237-247.

Verriere, V., Higgins, G., Al-Alawi, M., Costello, R. W., McNally, P., Chiron, R., et al. (2012). Lipoxin A4 stimulates calcium-activated chloride currents and increases airway surface liquid height in normal and cystic fibrosis airway epithelia. PLoS One 7:e37746. doi: 10.1371/journal.pone.0037746

Wang, H., Anthony, D., Yatmaz, S., Wijburg, O., Satzke, C., Levy, B., et al. (2017). Aspirin-triggered resolvin D1 reduces pneumococcal lung infection and inflammation in a viral and bacterial coinfection pneumonia model. Clin. Sci. 131, 2347-2362. doi: 10.1042/CS20171006

Weber, A. J., Soong, G., Bryan, R., Saba, S., and Prince, A. (2001). Activation of NF-kappaB in airway epithelial cells is dependent on CFTR trafficking and $\mathrm{Cl}^{-}$channel function. Am. J. Physiol. Lung Cell. Mol. Physiol. 281, L71-L78. doi: 10.1152/ajplung.2001.281.1.L71

Weiss, G. A., Troxler, H., Klinke, G., Rogler, D., Braegger, C., and Hersberger, M. (2013). High levels of anti-inflammatory and pro-resolving lipid mediators lipoxins and resolvins and declining docosahexaenoic acid levels in human milk during the first month of lactation. Lipids Health Dis. 12, 89. doi: 10.1186/1476-511X-12-89 
Winkler, J. W., Libreros, S., De La Rosa, X., Sansbury, B. E., Norris, P. C., Chiang, N., et al. (2018). Structural insights into resolvin D4 actions and further metabolites via a new total organic synthesis and validation. J. Leukocyte Biol. doi: 10.1002/JLB.3MI0617-254R

Wittamer, V., Franssen, J. D., Vulcano, M., Mirjolet, J. F., Le Poul, E., Migeotte, I., et al. (2003). Specific recruitment of antigen-presenting cells by chemerin, a novel processed ligand from human inflammatory fluids. J. Exp. Med. 198, 977-985. doi: 10.1084/jem.20030382

Wu, S.-H., Chen, X.-Q., Liu, B., Wu, H.-J., and Dong, L. (2013). Efficacy and safety of 15(R/S)-methyl-lipoxin A(4) in topical treatment of infantile eczema. Br. J. Dermatol. 168, 172-178. doi: 10.1111/j.1365-2133.2012.11177.x

Ye, R. D., Boulay, F., Wang, J. M., Dahlgren, C., Gerard, C., Parmentier, M., et al. (2009). International Union of Basic and Clinical Pharmacology. LXXIII. Nomenclature for the formyl peptide receptor (FPR) family. Pharmacol. Rev. 61, 119-161. doi: 10.1124/pr.109.001578

Zhu, M., Wang, X., Hjorth, E., Colas, R. A., Schroeder, L., Granholm, A.-C., et al. (2016). Pro-resolving lipid mediators improve neuronal survival and increase Abeta42 phagocytosis. Mol. Neurobiol. 53, 2733-2749. doi: 10.1007/ s12035-015-9544-0
Zolin, A., Orenti, A., Naehrlich, L., van Rens, J., Fox, A., Iansa, P., et al. (2017). European Cystic Fibrosis Society Patient Registry Annual Report 2015. 1-134. www.ecfs.eu/news/ecfs-patient-registry-2015-annual-report

Zurier, R. B., Sun, Y.-P., George, K. L., Stebulis, J. A., Rossetti, R. G., Skulas, A., et al. (2009). Ajulemic acid, a synthetic cannabinoid, increases formation of the endogenous proresolving and anti-inflammatory eicosanoid, lipoxin A4. FASEB J. 23, 1503-1509. doi: 10.1096/fj.08-118323

Conflict of Interest Statement: The authors declare that the research was conducted in the absence of any commercial or financial relationships that could be construed as a potential conflict of interest.

Copyright (c) 2019 Recchiuti, Mattoscio and Isopi. This is an open-access article distributed under the terms of the Creative Commons Attribution License (CC BY). The use, distribution or reproduction in other forums is permitted, provided the original author(s) and the copyright owner(s) are credited and that the original publication in this journal is cited, in accordance with accepted academic practice. No use, distribution or reproduction is permitted which does not comply with these terms. 